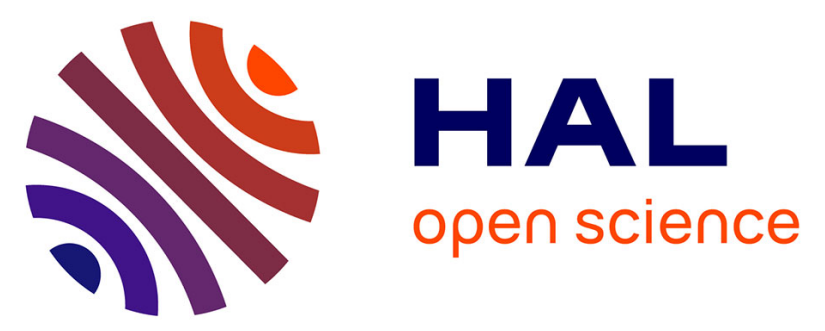

\title{
Liquid cooling of a microprocessor: experimentation and simulation of a sub-millimeter channel heat exchanger
}

Julien Fontaine, Charles Gonzalez, Prashant Kumar, François Pigache, Pascal Lavieille, Frédéric Topin, Marc Miscevic

\section{- To cite this version:}

Julien Fontaine, Charles Gonzalez, Prashant Kumar, François Pigache, Pascal Lavieille, et al.. Liquid cooling of a microprocessor: experimentation and simulation of a submillimeter channel heat exchanger. Heat Transfer Engineering, 2019, 41 (15-16), pp.1365-1381. 10.1080/01457632.2019.1628485 . hal-03079615v3

\section{HAL Id: hal-03079615 \\ https://hal.science/hal-03079615v3}

Submitted on 4 Feb 2022

HAL is a multi-disciplinary open access archive for the deposit and dissemination of scientific research documents, whether they are published or not. The documents may come from teaching and research institutions in France or abroad, or from public or private research centers.
L'archive ouverte pluridisciplinaire HAL, est destinée au dépôt et à la diffusion de documents scientifiques de niveau recherche, publiés ou non, émanant des établissements d'enseignement et de recherche français ou étrangers, des laboratoires publics ou privés.

\section{(ㅇ)(1) $\$$}

Distributed under a Creative Commons Attribution - NonCommercial - NoDerivatives 44.0 


\title{
Liquid Cooling of a Microprocessor: Experimentation and Simulation of a
} Sub-Millimeter Channel Heat Exchanger

\author{
Fontaine J. ${ }^{1}$, Gonzalez C. ${ }^{1,2}$, Kumar P. ${ }^{2}$, Pigache F. ${ }^{1}$, Lavieille P. ${ }^{1}$, Topin F. ${ }^{2}$, Miscevic M. ${ }^{1}$ \\ ${ }^{1}$ University of Toulouse, LAPLACE (Laboratory on Plasma and Conversion of Energy), Toulouse, France

(1)

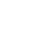




\section{$1 \quad$ ABSTRACT}

2 A heat exchanger dedicated to the cooling of a microprocessor has been designed and realized.

3 This heat exchanger consists of a bottom wall in contact with the processor and a cover that has

4 been dug to a depth of $200 \mu \mathrm{m}$ on one side and $1 \mathrm{~mm}$ on the other side. Thus, by turning the

5 cover, the hydraulic diameter of the channel can be changed. Both hydraulic and thermal

6 performances of this heat exchanger have been experimentally tested. At the same time, 3D

$7 \quad$ numerical simulations were carried out on a model of the experimental prototype. Comparisons

8 between numerical and experimental results are in good agreement. In particular, the influence

9 of the distributor and the collector on the distribution of fluid flow and heat fluxes is emphasized.

10 A new concept of micro heat exchanger was then proposed for the cooling of electronics devices

11 for which wall to fluid heat exchange quality as well as pumping effect is very critical. In the

12 present work, the ability of a liquid heat exchanger involving a dynamic deformation of one of its

13 walls to cool a microprocessor is investigated. For that purpose, 3D transient numerical

14 simulations of fluid flow and conjugate heat transfer were performed using commercial software

15 based on the finite volume. Effect of geometrical and actuation parameters has been explored

16 demonstrating the ability of such heat exchanger to simultaneously pump the fluid and enhance

17 the heat transfer. 


\section{INTRODUCTION}

The evacuation of the heat generated within a microprocessor is a crucial problem. It

3 affects the user from various points of view: limitation of performance and maximum allowable

4 temperature of the environment in which it can be used, drastic reduction in reliability and

5 lifetime, energy consumption of the chip. It is therefore necessary to develop efficient cooling

6 solutions even for high heat generation microprocessors and to keep it near its optimum operating

7 temperature. Numerous works have been conducted to propose new techniques to enhance heat

8 transfer and improve existing ones [1]. For application in high dissipative electronics, air-cooling

9 appears to be increasingly inappropriate due to low thermal conductivity as well as low density

10 and low heat capacity of this fluid. Thus, liquid or two-phase thermal management systems must

11 be developed. Furthermore, in addition to the rapid increase in the power density, electronic

12 packages are more and more miniaturized, implying to develop efficient cooling systems. Several

13 cooling solutions can then be envisaged. Among these solutions, micro channels-based heat

14 exchanger is often presented as one of promising cooling technologies [2-8]. For example, very

15 recently Kheirabadi and Groulx [8] have shown a device whose thermal resistance is varying

16 from $0.105 \mathrm{~K} / \mathrm{W}$ to $0.08 \mathrm{~K} / \mathrm{W}$ when the coolant (water) flowrate varies from $1.1 \mathrm{l} / \mathrm{min}$ to $3.8 \mathrm{l} / \mathrm{min}$

17 in a microchannel heat sink in which channels were $0.5 \mathrm{~mm}$ wide and $2.3 \mathrm{~mm}$ tall.

18 Yang et al. [9] have proposed a general optimization process for the thermo-hydraulic

19 performances of mini-channel heat sinks. They reported empirical correlations extracted from

20 literature and gave some recommendations about their use for practical design. Although many

21 works have already been carried out, thermo-hydraulic behavior and performances of such

22 miniature heat sinks are still to be explored [10,11].

23 Among these micro channel-cooling systems, those equipped with corrugated channels

24 appear particularly interesting. Heat transfer and pressure drop in sinusoidal corrugated channels 
1 have been studied by Nishimura et al. [12]. These authors showed that transition between laminar

2 and turbulent flows is obtained at lower Reynolds number $(R e=300)$ compared to straight

3 channel due to unsteady vortex motion. As for flat channel, the friction factor is inversely

4 proportional to Reynolds number in the laminar flow range, while it is independent of Reynolds

5 number in the turbulent one. Extending this study, Nishimura et al. [13] studied flow patterns

6 characteristics in symmetrical two-dimensional sinusoidal and arc-shaped corrugated channels at

7 moderate Reynolds numbers $(20<R e<300)$. They concluded that the transitional Reynolds

8 number depends on the corrugation shape and is lower for the arc-shaped wall.

9 Niceno and Nobile [14] have conducted an extended numerical study on these corrugated

10 channels. They found that these two corrugation shapes are ineffective in terms of heat transfer

11 rate (slightly higher for sinusoidal compare to arc-shaped channel) as compared to flat channel in

12 steady low Reynolds flow. The unsteady regimes appear at different Reynolds numbers for the

13 two corrugation shapes: unsteady regime was observed at $R e=60-80$ for arc-shaped channel

14 and at $R e=175-200$ for sinusoidal one. On the other hand, heat transfer rate increases

15 significantly for both corrugation shapes, up to a factor of three, as a result of self-sustained

16 oscillations. Moreover, this transfer rate was found to be higher for arc-shaped channel while the

17 friction factor was smaller for sinusoidal channel.

18 Naphon [15] conducted a numerical study on various corrugation geometries arranged in

19 in-phase and out-phase layouts (e.g. flat plate, arc-shaped, trapezoidal and V-shaped) to enhance

20 the thermal performances. He obtained that for a given air flow rate, V-shaped corrugated

21 channel enhances most heat transfer. This enhancement is linked to boundary layer disruption.

22 Most of the studies revealed an increase in overall thermal performance from 3 to 5 times

23 depending on the working fluid. However, static corrugated channels have shown to increase

24 significantly the pressure drop. In such corrugated (and grooved) mini-channels, high heat 
1 transfer usually leads to high Reynolds number (mostly turbulent) flow.

2 Yang et al. [16, 17] compared three different designs of a micro heat exchanger for use in a

3 liquid cooling system. Best thermal performances were obtained with the chevron channel heat

4 exchanger. Unfortunately, this heat exchanger was also the one generating the highest pressure 5 drops.

6 On the other hand, Léal et al. [18] proposed a relatively simple model of dynamic 7 corrugated mini-channel to be operated at low Reynolds number. This has been achieved by 8 deforming dynamically one of the channel walls. Very high heat transfer has been obtained 9 compared to static corrugated channel (with a relative gain in heat transfer coefficient of about $10400 \%$ ). It appeared to be the first study to introduce dynamic wall in such mini-channels heat 11 exchanger.

12 Very recently, Kumar et al. [19] extended this work and proposed a realistic 3D geometry 13 of dynamic corrugated heat exchanger. In their study, the average height of the channel is fixed 14 while the minimum gap (distance between the lowest point of the deformed wall and the fixed 15 wall) varies as a function of the relative amplitude. Numerical studies have been conducted for a 16 channel outlet pressure greater than the inlet one and for an imposed frequency of $50 \mathrm{~Hz}$. They 17 showed that heat transfer coefficient is proportional to wave amplitude and that such devices 18 possess self-pumping capacity. This system can operate with negligible pressure drop, or even 19 without an external pump.

20 The aim of this paper is to determine the ability of this type of actuated liquid heat 21 exchanger to cool a micro-electronic device. First, a reference (static) heat exchanger has been 22 studied, from both experimental and numerical point of view. A systematic numerical study was 23 then conducted considering a micro-heat exchanger using three actuators to deform dynamically 24 one of its walls to understand the impact of operating parameters in enhancing thermo-hydraulic 
characteristics.

\section{REFERENCE HEAT EXCHANGER}

\section{$4 \quad$ Experimental setup}

The reference exchanger consists of two parts, the sole made of copper and the cover made

6 of aluminum. Two grooves are machined in the sole and communicate with the inlet and outlet

7 pipes (see Figure 1). An O-ring is placed at the periphery for sealing. The cover is a simple

8 parallelepiped plate that has been dug to a depth of $200 \mu \mathrm{m}$ on one face and $1 \mathrm{~mm}$ on the other.

9 Thus, by turning the cover, the hydraulic diameter of the channel can be changed. The channel

10 obtained for the circulation of the fluid after assembly is thus rectangular with a cross-section of

$1150 \mathrm{~mm}$ in width, $38 \mathrm{~mm}$ in length (distance between the distributor and the collector) and is 200

$12 \mu m$ or $1 \mathrm{~mm}$ in height (Figure 2).

13 In order to be able to determine the thermal performance independently of the thermal

14 contact resistance between the exchanger and the microprocessor, three thermocouples were

15 inserted into the sole at a distance of $1 \mathrm{~mm}$ from the surface in contact with the liquid. These

16 thermocouples are K-type, sheathed in stainless steel, $500 \mu \mathrm{m}$ in diameter. The holes in the sole

17 were made by electro erosion; they have a diameter of $600 \mu \mathrm{m}$ and a length of $33 \mathrm{~mm}$. Two other

18 identical thermocouples are placed in inlet and outlet pipes along with pressure taps (diameter 4

$19 \mathrm{~mm}$ ) in order to measure the inlet and outlet bulk temperatures of the fluid. All thermocouples

20 have been calibrated against a certified Pt100 RTD probe (accuracy of $0.05{ }^{\circ} \mathrm{C}$ ). Thus, the

21 relative accuracy of temperature measurements is estimated at $0.1{ }^{\circ} \mathrm{C}$. A differential pressure

22 sensor is positioned between the inlet and outlet pipes of the heat exchanger (the connections are

23 located $25 \mathrm{~cm}$ upstream and downstream of the heat exchanger) and allows measuring the

24 pressure loss with an accuracy better than $10 \mathrm{~Pa}$. 
The heat source is constituted by a microprocessor mock-up supplied by Intel Company

2 and fixed to the sole. This mock-up is geometrically identical to a commercially available

3 processor and generates similar and easily scalable thermal solicitations.

4 The heat exchanger is connected to a hydraulic circuit (see schema in Figure 3). A counter-

5 current tubular heat exchanger is used as cold source for the fluid loop. The fluid then passes

6 through a Coriolis flowmeter allowing mass flow rate measurements in the range 0 up to $6 \mathrm{~g} / \mathrm{s}$

7 with an accuracy of $0.02 \mathrm{~g} / \mathrm{s}$. We thus obtained a maximum Reynolds number of 240 within the

8 heat exchanger for both considered thicknesses (hydraulic diameter respectively equal to 1960

$9 \mu \mathrm{m}$ and $398 \mu \mathrm{m})$. A variable speed gear pump is used for discharging the fluid into a precision

10 valve. This latter allows us to vary the pressure drop in the circuit at the desired value in a simple

11 manner. The fluid then flows toward the inlet of the heat exchanger prototype. A reservoir (open

12 to the atmosphere) is connected to the hydraulic circuit and serves as an expansion vessel. The

13 secondary fluid in this heat exchanger is thermostated water.

\section{Numerical simulation}

16 Simultaneously, direct numerical simulations of this heat exchanger were carried out using

17 commercial software Star- CCM+. The virtual prototype was constructed using the CAD model

18 of the assembly (bottom wall, top cover and channel). The conjugate heat transfer problem was

19 solved in the transient regime, and heat conduction is considered in all solid parts. Note that a

20 perfect thermal contact between top and bottom parts of the assembly was considered. For the

21 channel as well as inlet and outlet manifolds, incompressible laminar and transient flow and heat

22 transfer were solved using the classical combination of continuity, momentum and energy

23 equations (here simply written for constant properties): 


$$
\rho C_{p}\left(\frac{\partial T}{\partial t}+\vec{u} \cdot \vec{\nabla} T\right)+\rho \vec{u} \cdot \frac{\partial \vec{u}}{\partial t}+\frac{\rho}{2}\left(\vec{\nabla}\|\vec{u}\|^{2}\right) \cdot \vec{u}=k_{f} \Delta T+\frac{\partial P}{\partial t}+\varnothing
$$

3 Where $\emptyset$ is the volumetric energy source due to viscous dissipations. This term is taken into 4 account during all calculations; however, in the present work, it is negligible compared to the 5 wall heat transfer.

6 The physical properties of the fluid were considered to vary with the temperature (water 7 using the models of IAPWS-IF97 (International Association for the Properties of Water and

8 Steam, Industrial Formulation 1997) while the solid part properties are supposed constant (copper

9 for the base and aluminum for the top cover). The numerical resolution used a segregated 10 approach with implicit second order temporal discretization and ad hoc relaxations factors in 11 order to obtain adequate convergence behavior. 1691272 and 1852205 meshes were used for 12 the $1 \mathrm{~mm}$ and the $200 \mu \mathrm{m}$ heat exchanger, respectively. For both cases, an unstructured trimmer 13 octree mesh type- is used in solid parts while structured hexahedral anisotropic cells are used in

14 the channel with 16 up to 20 cells along the height of the channel. This mesh is refined in the 15 vicinity of all solid-fluid interfaces and near inlet and outlet of the channel. Mesh convergence 16 effects were checked, and no additional improvement is obtained with further refinement.

17 Both mass flow rate and fluid temperature were imposed at the inlet of the heat exchanger; 18 outlet pressure is imposed at the atmospheric one. A uniform heat flux is imposed on the bottom 19 wall of the sole, on an area of $30 \times 30 \mathrm{~mm}^{2}$ as in the experiments. The rest of the solid walls are 20 considered adiabatic (as experimental results show that thermal losses are negligible).

\section{NUMERICAL ACTUATED PROTOTYPE}

23 In the studied configuration, the lower wall was fixed and subjected to a constant heat flux 
1 along the imprint of heating zone while the dynamically deformed upper wall (also called

2 "membrane" in the following) and side walls were kept adiabatic. Several actuators were

3 employed to dynamically deform the upper wall of a rectangular cross section micro-channel in

4 order to simultaneously enhance heat transfer and pump the fluid.

5 The length of the actuated zone $(L)$ is $49 \mathrm{~mm}$ while width $(W)$ is $35 \mathrm{~mm}$. The channel gap

6 (g) is fixed and is $10 \mu \mathrm{m}$ while the average height of the channel $(\delta)$ is linked to the wave

7 amplitude employed for wall deformation and the channel gap. The lengths of input and outlet

8 zones have been chosen long enough to establish the hydrodynamic. Furthermore, the no-slip

9 condition was imposed on the walls.

10 The influences of relative amplitude $\left(A_{0}\right)$, frequency $\left(f_{r}\right)$ and wavelength $(\lambda)$ on thermo-

11 hydraulic performances are studied for an imposed value of the pressure difference between

12 outlet and inlet of the exchanger equal to zero.

13 Only three actuators were employed in the present study. The channel cross-section shape

14 is presented on Figure 4 where the actuator positions can be described using $x_{1}, x_{2}, x_{3}, x_{4}, x_{5}$ and

$15 x_{6}$. The positions $x_{0}$ and $x_{7}$ are fixed to external inlet and outlet zones as dampers. These small

16 zones make the fluid to enter and leave in laminar condition. The micro-channel geometry is

17 composed of four main parts: inlet zone, heated surface where the heat power is imposed, outlet

18 zone and membrane. This simplified geometrical configuration, dedicated to study the impact of

19 actuators operating parameters ( 3 actuators case) do include sidewall-damping effects on the

20 lateral side of the actuated zone. Along main flow axis the membrane displacement is linearly

21 interpolated between actuators pair and between actuator and fixed zone.

$223 \mathrm{D}$ numerical simulations were carried out using the commercial software StarCCM+. This

23 software allows modeling fluid flow and heat transfer in dynamically deformed structures. The

24 flow was considered transient, three-dimensional and laminar. The working fluid was liquid 
1 water (properties taken from IAPWS-97 at $27^{\circ} \mathrm{C}$ ) whose all thermo-physical properties were

2 supposed constant for systematic studies. The imposed heat power on the imprint (heated zone)

3 was $65 W$ (note that only half of the device is modeled due to symmetry).

$4 \quad$ The results presented focus on the "active zone" namely between $S_{1}$ and $S_{2}$ sections (see

5 Figure 4). All representative global thermo-hydraulic quantities were calculated in this zone.

6 The incompressible laminar and transient conjugate flow and heat transfer problems were

7 solved as for the static heat exchanger. The numerical resolution used a segregated approach with

8 implicit second order temporal discretization and ad hoc relaxations factors in order to obtain

9 adequate convergence behavior. The displacement of the top membrane is created by:

10 (1)- fixing it in inlet and outlet zone and displacing the upper wall at chosen height $\delta$ 11 (average height of the channel),

12 (2)- adding the movement of the three actuators (Eq. 4),

13 (3)- in between two actuators or one actuator and border, the displacement is simply 14 interpolated.

15 The displacement of actuator is given by the following equation for $i=1,2,3$ corresponding

16 to actuator along main flow axis:

$$
\operatorname{Act}_{i}(x, t)=A_{o} \cdot \cos \left(2 \pi f_{r} t+\Phi_{i}\right)
$$

18 where $\Phi_{1}=0^{\circ}, \Phi_{2}, \Phi_{3}$ are phase of actuators $A c t_{1}, A c t_{2}$ and $A c t_{3}$, respectively.

19 In the studied configuration, the vertical plane passing through the central axis of the 20 channel is a plane of symmetry, so only half of the channel was simulated (i.e. $W / 2=17.5 \mathrm{~mm}$ ).

21 The imposed power on the modeled half-imprint was thus $32.5 \mathrm{~W}$ to carry out numerical

22 simulations (see Figures 4 and 5). This allows us to reduce the number of mesh cells to optimize 23 computation time by dividing the simulated configuration by two compared to its actual size.

24 Note that the fluid flow was considered in $\mathrm{x}$-direction while the width and height of the channel 
1 were considered in y- and z-directions, respectively.

2 Meshing strategy was similar to the one used by Kumar et al. [19]. It was rather tricky to

3 create a convenient mesh in such highly anisotropic geometrical configuration subjected to large

4 amplitude deformations (up to $98 \%$ of channel height) while keeping a computational time low

5 enough to carry out parametric study without sacrificing precision or convergence of the dynamic

6 transfer.

$7 \quad$ The deformed channel mesh is presented in Figure 5 in case of an actuator size of $11 \mathrm{~mm}$ 8 and a phase-shift between two consecutive actuators of $120^{\circ}\left(\Phi=0^{\circ},-120^{\circ},-240^{\circ}\right)$.

9 In case of dynamic corrugated channel, surface averaged and volume averaged thermo-

10 hydraulic quantities for all operating configurations were calculated as follow. The Reynolds

11 number and hydraulic diameter are defined by:

$$
R e=\frac{\rho\|\vec{u}\| D_{h}}{\mu}, D_{h}=\frac{1}{\lambda} \int_{0}^{\lambda} \frac{4 S}{p} d \lambda
$$

13 Where $S$ is the flow fluid passage area along the heated zone and $p$ is the perimeter of the

14 passage section, respectively. Note that these quantities are averaged over a time period.

15 Following the method used in Léal et al. [18], the heat transfer coefficient is obtained by the

16 spatial and temporal averaged fluid temperature and wall temperature over the width and between

17 sections $S_{1}$ and $S_{2}$ (distance $\left.L\right)$ as well as over a period $\left(\tau=1 / \mathrm{f}_{\mathrm{r}}\right)$ :

$$
\bar{T}_{w}=\frac{1}{\tau W L} \int_{t}^{t+\tau} \int_{S 1}^{S 2} \int_{0}^{W} T_{w}(x, y, t) d x d y d t
$$

$$
\bar{T}_{m f}=\frac{1}{\tau \delta W L} \int_{t}^{t+\tau} \int_{S 1}^{S 2} \int_{0}^{z(x, t)} \int_{0}^{W} T_{m f}(x, y, z, t) d x d y d z d t
$$

20 In the following, the global heat transfer coefficient and Nusselt number across the channel 21 (between S1 and S2) are defined as:

$$
\langle h\rangle=\frac{\Gamma}{\left(\bar{T}_{w}-\bar{T}_{m f}\right)},\langle N u\rangle=\frac{\langle h\rangle D_{h}}{k_{f}}
$$


The calculations to test mesh convergence were performed for amplitude $A_{0}=85 \mu \mathrm{m}$ and

2 frequency $f_{r}=20 \mathrm{~Hz}$. We initialized both corrugated shape and fluid flow. Then, calculations

3 were carried out until a periodic stationary regime is reached. This latter point is checked

4 comparing the temporal evolutions of global heat transfer and flow characteristics: calculations

5 were performed until the heat transfer coefficient values between two consecutive time periods

6 differs by less than $1 \%$. Consequently, an additional time period is added to extract all

7 instantaneous and time-averaged values of all physical quantities.

8 From the Table 1, it can be seen that reducing the characteristic mesh size from 3 to $2 \mathrm{~mm}$

9 does not impact strongly on the global properties. The percentage differences between the

10 properties are respectively: $0.14 \%$ for $\dot{m}, 0.0024 \%$ for $T_{W}, 0.006 \%$ for $T_{m f}, 0.47 \%$ for $\langle h>$,

$110.0095 \%$ for $T_{f i}$ and $0.0095 \%$ for $T_{f o}$. On increasing the mesh size, these quantities vary

12 significantly while reducing it further do not lead to any additional improvement. Based on these

13 observations and the percentage difference in the properties, we chose the BMS (Base Mesh Size)

14 equal to $2 \mathrm{~mm}$ to perform the systematic studies.

15 To perform the numerical simulations in terms of time effectiveness as well as the

16 precision, it is very important to obtain an optimized time step (TS). We test the following

17 number of time steps per period: 20, 50, 75 and 100. Based on these time steps, global

18 characteristics have been presented in Table 2. It can be observed that heat transfer coefficient

19 values decrease with increase in $T S$. On the other hand, $\Delta T_{m}=T_{w}-T_{m f}$ increases with increase in $20 T S$.

21 In order to obtain an optimized $T S$ value, we have calculated the percentage variation of $22\left\langle h>\right.$ and $\Delta T_{m}$ for different time steps based on the lowest value as a reference value for both 23 these quantities. When $T S=50$, we observed a variation of $\langle h\rangle$ equal to $2.84 \%$ while the 24 variation in $\Delta T_{m}$ is $6.14 \%$. The global results of different characteristics do not vary strongly 
1 when increasing TS. Moreover, higher value of TS increases the computational time while the

2 properties vary within a difference of $3 \%$. Hence, $T S=50$ has been chosen to study the impact of

3 different amplitudes and frequencies.

\section{HYDRAULIC RESULTS}

\section{$7 \quad$ Hydraulic behavior of the reference heat exchanger}

A first series of experimental tests and numerical simulations were carried out without

9 powering the processor, at a temperature of $20^{\circ} \mathrm{C}$, in order to characterize the heat exchanger

10 from hydraulic point of view. The pressure losses obtained as a function of the mass flow rate are

11 reported in Figure 6 for the two considered channel thicknesses (200 $\mathrm{mm}$ and $1 \mathrm{~mm}$ ). Globally,

12 experiments and numerical simulations exhibit the same trend. Nevertheless, significant

13 discrepancies are found between experimental and numerical results, especially for the $1 \mathrm{~mm}$

14 channel. These discrepancies can be explained by the fact that the pressure losses in the

15 numerical simulations are determined between the inlet and the outlet of the heat exchanger,

16 while in the experiments the tappings for the pressure measurement are located at $25 \mathrm{~cm}$ upstream

17 and $25 \mathrm{~cm}$ downstream of the prototype. Thus, additional pressure losses are taken into account in

18 the experiments (regular pressure drop in the inlet and outlet tubes, as well as singular pressure

19 drops in the connections between the tubes of the loop and the heat exchanger).

20 Furthermore, in the $1 \mathrm{~mm}$ channel heat exchanger, the flow distribution appears less

21 homogeneous than in the $200 \mu \mathrm{m}$ channel heat exchanger, as it can be seen in Figures 7 and 8 ,

22 respectively. Such a flow maldistribution variation according to the channel hydraulic diameter is

23 not surprising: it has widely been highlighted. For example, Kheirabadi and Groulx [4]

24 numerically calculated variation of the mean velocity from a channel to another in an array of 
1 parallel microchannels connected to a single manifold at the inlet and at the outlet. Variation up

2 to $52 \%$ was highlighted for the $1 \mathrm{~mm}$ microchannel width, while this variation was only $16 \%$ for

3 the $0.25 \mathrm{~mm}$ microchannel width. In the present study, the flow distribution in the $1 \mathrm{~mm}$ channel

4 heat exchanger could be homogenized by optimizing the distributor and collector headers as

5 suggested, for instance, by Saeed and Kim [20]. From these figures, it can be speculated that the

6 main part of the pressure drop in the $200 \mu m$ channel heat exchanger is the regular pressure drop

7 in the channel itself, while in the $1 \mathrm{~mm}$ the main part of the pressure drop corresponds to the

8 pressure drop in the singularities and in the manifolds.

9 To assess the respective contributions of the channel and the singularities on the total 10 pressure drop, an analytical estimation can be done. Assuming a Poiseuille flow in the inlet and

11 outlet tubes, as well as in the channel, the pressure drop can be calculated as:

$$
\Delta p=\frac{64}{R e_{D_{t}}} \frac{L_{t}}{D_{t}} \frac{1}{2} \rho U_{t}^{2}+\frac{64}{R e_{D_{h}}} \frac{L_{c}}{D_{h}} \frac{1}{2} \rho U_{c}^{2}+\sum_{i} \xi_{i} \frac{1}{2} \rho U_{c}^{2}
$$

13 With:

$$
R e_{D_{t}}=\frac{\rho U_{t} D_{t}}{\mu}, R e_{D_{h}}=\frac{\rho U_{c} D_{h}}{\mu} \quad \text { with } D_{h}=\frac{4 e l}{2(e+l)} \approx 2 e
$$

The last term in equation 10 represents the pressure drop due to all the singularities. The

16 value of $\sum_{i} \xi_{i}$ is adjusted to reproduce the experimental pressure drop of the $1 \mathrm{~mm}$ channel heat

17 exchanger: $\sum_{i} \xi_{i} \approx 5$.

18 The global pressure losses of the device equipped with the $200 \mu \mathrm{m}$ channel heat exchanger

19 are 2 to 2.5 times higher than those measured with the one using the $1 \mathrm{~mm}$ channel heat

20 exchanger, while the hydraulic diameter is 5 times lower. This behavior can be explained by

21 analyzing the part of the regular pressure losses in comparison with the singular pressure losses

22 corresponding to the different changes in flow direction and cross-sections. These relative

23 contributions are shown in Figure 10. For the $1 \mathrm{~mm}$ channel heat exchanger, the pressure losses in 
1 the actual channel are negligible, less than $2 \%$ of the total pressure losses. For the $200 \mu \mathrm{m}$

2 channel, these pressure losses in the channel become preponderant and represent 60 to $70 \%$ of

3 the total pressure losses. The superimposed graph on Figure 10 compare the numerical pressure

4 drop along each minichannel with the theoretical values deduced from established Poiseuille flow

5 model. A fair agreement is obtained in both case, the numerical value being globally about $10 \%$

6 higher than the theoretical one, this is due to the inlet-outlet effect along with maldistribution.

\section{Hydraulic behavior of the virtual dynamic prototype}

9 Local fields are presented for the dynamic heat exchanger with $A_{0}=100 \mu \mathrm{m}$ and $f_{r}=10 \mathrm{~Hz}$

10 for arbitrary time during periodic stationary regime. During expansion of the dynamic channel,

11 the fluid moves in the longitudinal direction because of the successive expansion and

12 contractions. Wall movement induces also vertical (i.e. towards heated wall) displacement of the

13 fluid. Characteristic times associated to vertical and horizontal fluid displacement are similar and

14 significantly lower than the actuation one.

15 Mass flow rate is proportional to both frequency and amplitude. High frequency leads to

16 fast movement of the corrugated wall, which in turn enhances the mass flow. The latter is

17 therefore directly proportional to the frequency (Figure 12 top). Increasing amplitude (at constant

18 gap) leads to increase the channel volume thus to have more fluid in the channel. This behavior

19 also enhances mass flow rate in the system, which is also directly proportional to the amplitude

20 (Figure 12 bottom). Note that increasing amplitude at constant gap adds mainly volume to the

21 channel near the membrane and increases average height.

22 Influence of gap size has been tested on mass flow rate and heat transfer for amplitude 100

$23 \mu \mathrm{m}$ and frequency $10 \mathrm{~Hz}$. The initial gap was fixed at $10 \mu \mathrm{m}$ and then varied up to $35 \mu \mathrm{m}$. On

24 Figure 13, it can be easily observed that mass flow rate decreases with increasing gap. This 
1 indicates that global efficiency of such device is largely affected by the minimum constriction

2 height.

4 THERMAL PERFORMANCE

\section{Reference heat exchanger}

6 In order to determine the heat performance of the two configurations of the heat exchanger,

7 specific tests were carried out. The experimental protocol consists in imposing a water flow rate

8 by means of the gear pump and then supplying the microprocessor simulator with an electrical

9 power such that the water temperature difference between the inlet and the outlet is equal to

$1010 \pm 0.2{ }^{\circ} \mathrm{C}$. The inlet temperature of the water in the exchanger is imposed at $23.5^{\circ} \mathrm{C}$ for all the

11 tests. The deviations between the applied electric power and the heat flux received by the water

12 (quantified by multiplying the mass flow rate with the enthalpy variation) vary between 0 and 7

$13 \%$ and are on average $4 \%$.

14 The mean temperature $\left\langle T_{w}\right\rangle$ of the bottom wall of the heat exchanger is evaluated by 15 performing a $2^{\text {nd }}$ order polynomial regression of the measured wall temperatures and then

16 integrating this regression between the inlet and the outlet of the channel (i.e. between the outlet

17 of the distributor and the inlet of the collector, on a distance of $38 \mathrm{~mm}$ ). It should be noted that

18 this calculation represents only an estimation of the mean temperature because it does not take

19 into account the 2D distribution of the surface temperature (variation in the direction

20 perpendicular to the main axis of the flow). The average fluid temperature $\left\langle T_{f}\right\rangle$ is estimated by

21 performing an arithmetic mean between the inlet and outlet water bulk temperatures. Considering

22 the operating conditions described above, this average temperature of the water in the heat

23 exchanger is substantially constant for all the experiments and is equal to $28.5^{\circ} \mathrm{C}$. An "apparent" 
1 overall thermal conductance $G$ of the heat exchanger is then defined as:

2

11 case will impose a cold source at a temperature relatively close to the maximum allowable

12 processor temperature (e.g. $70^{\circ} \mathrm{C}$ ) along with limitations on the flowrate. In such conditions, heat

13 flux up to $125 \mathrm{~W}$ can be removed from the microprocessor with a mass flowrate of $3 \mathrm{~g} / \mathrm{s}$. The

14 temperature of the bottom wall of the heat exchanger would be only about $8{ }^{\circ} \mathrm{C}$ higher than the

15 fluid mean temperature. For a mass flow rate of about $5.4 \mathrm{~g} / \mathrm{s}$ up to $225 \mathrm{~W}$ could be removed with

16 a wall to fluid temperature difference of less than $20{ }^{\circ} \mathrm{C}$ (e.g. automotive applications). Finally,

17 increasing the mass flow rate up to $9 \mathrm{~g} / \mathrm{s}$, the actuated channel allows to extract $375 \mathrm{~W}$ with a wall

18 to fluid temperature of $30^{\circ} \mathrm{C}$. This device is thus also an efficient solution for data center type

19 applications. Moreover, contrarily to static mini/microchannels which generate prohibitory high

20 pressure drop and fluid maldistributions when operated in parallel, the active heat exchanger -due

21 to the pumping effect- constitute a best suited device for low pressure losses and well-distributed

22 flow in parallel branches of a fluid network. It can thus be concluded that such a heat sink can be

23 efficiently integrated to the different constraints of applications involving microprocessor thermal 
management.

2 Numerical simulations have been performed in the same conditions than the experiments

3 (i.e. inlet water temperature equal to $23.5{ }^{\circ} \mathrm{C}$, heat flux adjusted to obtain a temperature

4 difference between inlet and outlet of $10^{\circ} \mathrm{C}$ ). Virtual temperature sensors are placed at the same

5 locations than the experimental ones and data are extracted from the numerical temperature field.

6 The same procedure than - used in the experiments is then applied to calculate the apparent

7 overall thermal conductance; numerical results are reported along with experimental ones (Figure

$814)$.

9 Adequacy between experimental and numerical results is excellent for the $200 \mu m$ channel

10 heat exchanger, while the numerical simulations slightly overestimate the overall thermal

11 conductance in the case of the $1 \mathrm{~mm}$ channel heat exchanger. As mentioned in the hydraulic

12 behavior section, the flow in the $1 \mathrm{~mm}$ channel is non-uniformly distributed. This maldistribution

13 of the flow implies that the temperature field of the fluid is farther from a one-dimensional field

14 than in the case of the $200 \mu \mathrm{m}$ channel (see Figures 15 and 16). Calculating the mean temperature

15 of the fluid by integrating a second order polynomial trend curve as described above is therefore

16 less precise in the case of the $1 \mathrm{~mm}$ channel than in the case of the $200 \mu \mathrm{m}$ channel. In the case of

17 the $1 \mathrm{~mm}$ channel heat exchanger, the flow field is more sensitive to the deviation in the imposed

18 inlet conditions and geometry compared to the real ones. It is thus not surprising to obtain a better

19 match between numerical results and experiments in the case of the best-distributed flow.

\section{Numerical prototype}

22 Due to movement of the channel wall, cold fluid is moved near the heated wall successively

23 at every location; this boundary layer disruption increases sharply heat transfer along with mixing 
1 that takes place within the core flow. On temperature field, successive hot and "cold" plumes"

2 could be seen (Figure 17). Near inlet cold fluid fill the pocket during expansion, then is driven

3 toward heated surface, and eventually transferred below the next actuated zone. The constricted

4 zone acts as a barrier separating inlet and outlet parts. This leads the fluid to fill expansion zone

5 while being mixed efficiently; it is then transferred in the next pocket over time. These "bursts"

6 repeat cyclically along with mixing thus increasing heat transfer.

$7 \quad$ Heat transfer coefficient depends on both imposed frequency and amplitude. Increasing

8 frequency increases the mixing effect and the fluid velocity. Thus, it results in high heat transfer

9 coefficients varying roughly proportionally to the frequency (see Figure 18.a). On the other hand,

10 increasing amplitude -while keeping the gap (minimum height below actuators) constant- leads to

11 increase the average height of the channel and thus reduces the heat transfer coefficient. This one

12 is thus found to decrease linearly with the amplitude (see Figure 18.b). Nevertheless, the heat

13 transfer coefficient remains very high (greater than $10000 \mathrm{~W} / \mathrm{m}^{2} \mathrm{~K}$ ) for all tested cases. This is

14 due two main effects: the average fluid thickness increases, and the fluid velocities decrease.

15 Mainly the most constricted zones become less and less efficient as the gap increases. As these

16 zone (which cross all the channel length) are the place where the most efficient heat transfer takes

17 place, it is not surprising to observe a net decrease in heat transfer coefficient. Two main

18 conclusions could be drawn from these results: although the heat transfer coefficient decreases

19 when increasing channel height, for sub-millimeter cases it remains high enough to produce a

20 very small thermal resistance compared to the other involved in a chip cooling assembly (e.g.

21 contact resistances...). As, the flow increases with channel height, the need to remove relatively

22 high power with limited inlet-outlet temperature difference will by a more important design

23 parameter. Moreover, required pumping power and mechanical effort and constraints will be

24 more easily meet for channel with "large" dimensions i.e. going more toward one millimeter than 
2 A global thermal conductance of the virtual prototype can be derived from these heat

3 transfer coefficient values. The variation of this conductance is reported on Figure 19 along with

4 the experimental ones of the reference heat exchanger for both $1 \mathrm{~mm}$ and $200 \mu \mathrm{m}$ channel

5 thickness. When the channel wall is actuated a sharp heat transfer enhancement is obtained: for a

6 mass flow rate of $1 \mathrm{~g} / \mathrm{s}$ the thermal conductance of the virtual prototype is almost the triple than

7 the one of the $200 \mu \mathrm{m}$ reference heat exchanger (corresponding thus to an enhancement of

8 approximately $200 \%$ ). For a mass flow rate of $3 \mathrm{~g} / \mathrm{s}$ the enhancement is almost $100 \%$.

9 The thermal conductance of the virtual prototype appears thus very high. for example, as a

10 comparison point, [8] have developed several prototypes of very compact heat exchangers for the

11 cooling of electronics. They obtained a thermal conductance of $26 \mathrm{~W} / \mathrm{K}$ considering a serpentine

12 channel with a mass flow rate of $18 \mathrm{~g} / \mathrm{s}$ (leading to a pressure drop of $14700 \mathrm{~Pa}$ ). These thermal

13 conductance is very close from the one obtained with the virtual prototype with a mass flow rate

14 of $3 \mathrm{~g} / \mathrm{s}$ (with an imposed zero pressure difference). So, the actuated heat exchanger appears as a

15 good candidate when efficient cooling is needed.

\section{CONCLUSION}

18 An experimental setup and a numerical tool have been built in order to analyze

19 hydrothermal performances of heat sink with low diameter channel. For the $1 \mathrm{~mm}$ channel heat

20 exchanger, it was found that the main contribution in the pressure drop is due to the singularities

21 and the tubes upstream and downstream of the heat exchanger, and that the flow is badly

22 distributed in the channel. For the $200 \mu \mathrm{m}$ channel, the main contribution in the pressure drop is

23 due to the pressure loss in the channel itself, and the maldistribution is not significant. From heat

24 transfer point of view, the $200 \mu \mathrm{m}$ channel heat exchanger allows reaching thermal conductance 
1 up to $15 \mathrm{~W} / \mathrm{K}$ with a very low mass flow rate of $3 \mathrm{~g} / \mathrm{s}$. This thermal performance demonstrates

2 that such a liquid cooling heat sink could be efficiently used for the thermal management of

3 electronic chip like microprocessor. Nevertheless, important improvements in the thermo-

4 hydraulic performance could be obtained by optimizing the internal design.

5 Integration of the pumping function within a heat exchanger can be obtained considering

6 dynamic morphing of at least one of the wall of this heat exchanger. In addition, this dynamic

7 morphing may conduct to a significant heat transfer enhancement, making the concept

8 particularly interesting for embedded thermal management systems. A numerical tool has been

9 developed that allows determining the thermo-hydraulic performances of such a heat exchanger.

10 To meet the application constrains, the dynamic deformation has to be realized with a small

11 number of actuators. So, only 3 actuated zones are considered in the present work. It has then

12 been established that:

13 - The mass flow rate is mainly controlled by the frequency and amplitude of the

14 deformation, as well as the gap;

$15 \quad$ - High heat transfer coefficient values can be obtained, up to $20000 \mathrm{~W} / \mathrm{m}^{2} \mathrm{~K}$;

16 - The corresponding thermal conductance variation according to the mass flow rate is

17 almost twice the one of the $200 \mu m$ reference static heat exchanger. In addition to the integration

18 of the pumping function within the heat exchanger, important heat transfer enhancement is thus

19 obtained.

21 NOMENCLATURE

22

$23 A_{o} \quad$ relative amplitude, dimensionless

$24 \quad C_{p} \quad$ specific thermal capacity, $\mathrm{J} \mathrm{kg}^{-1} \cdot \mathrm{K}^{-1}$

$25 \quad D_{h} \quad$ hydraulic diameter, $\mathrm{m}$ 


\begin{tabular}{|c|c|c|}
\hline 1 & $f_{r}$ & frequency, $\mathrm{Hz}$ \\
\hline 2 & $g$ & minimum gap of the channel, $\mathrm{m}$ \\
\hline 3 & $h$ & mean heat transfer coefficient at the heated wall, $\mathrm{W} \cdot \mathrm{m}^{-2} \cdot \mathrm{K}^{-1}$ \\
\hline 4 & $\langle h\rangle$ & global heat transfer coefficient at the heated wall, $\mathrm{W} \cdot \mathrm{m}^{-2} \cdot \mathrm{K}^{-1}$ \\
\hline 5 & $k_{f}$ & fluid thermal conductivity, $\mathrm{W} \cdot \mathrm{m}^{-1} \cdot \mathrm{K}^{-1}$ \\
\hline 6 & $L$ & imprint length of heated zone, $\mathrm{m}$ \\
\hline 7 & $\dot{m}$ & mass flow rate, $\mathrm{kg} . \mathrm{s}^{-1}$ \\
\hline 8 & $q$ & heat flux, W.m ${ }^{-2}$ \\
\hline 9 & $P_{g}$ & pressure gain in actuated zone, $\mathrm{Pa}$ \\
\hline 10 & $\Delta P$ & pressure difference between outlet-inlet sections, $\mathrm{Pa}$ \\
\hline 11 & $P_{P}$ & pumping power, $\mathrm{W}$ \\
\hline 12 & $p$ & perimeter of the channel passage, $\mathrm{m}$ \\
\hline 13 & $S$ & exchange surface, $\mathrm{m}^{2}$ \\
\hline 14 & $t$ & time, $\mathrm{s}$ \\
\hline 15 & $\bar{T}_{f m}$ & mean fluid temperature at a given axial position, $\mathrm{K}$ \\
\hline 16 & $\left\langle\bar{T}_{f m}\right\rangle$ & mean fluid temperature in the channel, $\mathrm{K}$ \\
\hline 17 & $\bar{T}_{w}$ & mean wall temperature on a heated zone, $\mathrm{K}$ \\
\hline 18 & $\left\langle\bar{T}_{w}\right\rangle$ & mean wall temperature in the actuated zone, $\mathrm{K}$ \\
\hline 19 & $\|\vec{u}\|$ & average velocity, $\mathrm{m} \cdot \mathrm{s}^{-1}$ \\
\hline 20 & $W$ & channel width, $\mathrm{m}$ \\
\hline & \multicolumn{2}{|c|}{ Special characters } \\
\hline 21 & $\delta$ & average distance between walls, $\mathrm{m}$ \\
\hline 22 & $\Gamma$ & total solid to fluid heat transfer, $\mathrm{W}$ \\
\hline 23 & $\varnothing$ & volumic heat source, $\mathrm{W} \cdot \mathrm{m}^{-3}$ \\
\hline 24 & $\rho$ & fluid density, kg.m ${ }^{-3}$ \\
\hline 25 & $\lambda$ & wavelength, m \\
\hline 26 & $\omega$ & number of waves per unit length, $\mathrm{m}^{-1}$ \\
\hline 27 & $\mu$ & dynamic viscosity, $\mathrm{kg} \cdot \mathrm{m}^{-1} \cdot \mathrm{s}^{-1}$ \\
\hline 28 & $\xi$ & pressure drop coefficient, dimensionless \\
\hline 29 & $\tau$ & period, s \\
\hline
\end{tabular}




\section{ACKNOWLEDGMENT}

3 This work has been realized in the framework of the CANOPEE project and supported by

4 the "Fond Unique Interministériel (FUI) - 18th call for projects". We gratefully acknowledge

5 contributions from all project partners.

6

\section{REFERENCES}

8 [1] Léal L., Miscevic M., Lavieille P., Amokrane M., Pigache F., Topin F., Nogarède B., and

9 Tadrist L., An overview of heat transfer enhancement methods and new perspectives: focus on 10 active methods using electroactive materials, Int. J. Heat Mass Transf., vol. 61, pp. 505-524,

112013

12 [2] Xie X.L., Liu Z.J., He Y.L., and Tao W.Q., Numerical study of laminar heat transfer and 13 pressure characteristics in a water-cooled minichannel heat sink, Applied Thermal Engineering, 14 vol. 29, pp. 64-74, 2009

15 [3] Tullius JF., Vajtai R., and Bayazitoglu Y., A review of cooling in microchannels, Heat 16 Transfer Engineering, vol. 32, no. 7-8, pp. 527-541, 2011.

17 [4] Kheirabadi A.C., and Groulx D., A comparison of numerical strategies for optimal liquid 18 cooled heat sink design, Proceedings of the ASME 2016 Summer Heat Transfer Conference,

19 Paper HT2016-7076, July 10-14, Washington DC, USA, 2016.

20 [5] Kheirabadi A.C., and Groulx D., Cooling of server electronics: a design review of existing 21 technology, Applied Thermal Engineering, vol. 105, pp. 622-638, 2016.

22 [6] Sohel Murshed S.M., and Nieto de Castro C.A., A critical review of traditional and emerging 23 techniques and fluids for electronics cooling, Renewable and Sustainable Energy Reviews, vol. 24 78, pp. 821-833, 2017. 
1 [7] Habibi Khalaj A., and Halgamuge S.K., A Review on efficient thermal management of air-

2 and liquid-cooled data centers: From chip to the cooling system, Applied Energy, vol. 205, pp.

$3 \quad 1165-1188,2017$.

4 [8] Kheirabadi A.C., and Groulx D., Experimental evaluation of a thermal contact liquid cooling

5 system for server electronics, Applied Thermal Engineering, vol. 129, pp. 1010-1025, 2018.

6 [9] Yang X.H., Tan S.C., Ding Y.J., and Liu J., Flow and thermal modeling and optimization of

7 micro/mini-channel heat sink, Applied Thermal Engineering, vol. 117, pp. 289-296, 2017.

8 [10] Dixit T., and Ghosh I., Review of micro- and mini-channel heat sinks and heat exchangers

9 for single phase fluids, Renewable and Sustainable Energy Reviews, vol. 41, pp. 1298-1311, 102015.

11 [11] Ghani I.A., Sidik N.A.C., and Kamaruzaman N., Hydrothermal performance of 12 microchannel heat sink: The effect of channel design, International Journal of Heat and Mass

13 Transfer, vol. 107, pp. 21-44, 2017.

14 [12] Nishimura, T., Ohori, Y., and Kawamura, Y., Flow characteristics in a channel with 15 symmetric wavy wall for steady flow, Journal of Chemical Eng. of Japan, Vol., 17, no. 5, pp. 16 466- 471, 1984.

17 [13] Nishimura, T., Murakami, S., Arakawa, S., and Kawamura, Y., Flow observations and mass 18 transfer characteristics in symmetrical wavy-walled channels at moderate Reynolds numbers for 19 steady flow, International Journal of Heat and Mass Transfer, Vol. 33, no. 5, pp. 835-845, 1990.

20 [14] Niceno, N., and Nobile, E., Numerical analysis of fluid flow and heat transfer in periodic 21 wavy channels, International Journal of Heat and Fluid Flow, Vol. 22, pp. 156-167, 2001.

22 [15] Naphon, P., Effect of wavy plate geometry configurations on the temperature and flow 23 distributions, International Com. On Heat and Mass Transfer, Vol. 36, pp. 942-946, 2009.

24 [16] Yang C.Y., Yeh C.T., Liu W.C., and Yang B.C., Advanced micro-heat exchangers for high 
1 heat flux, Heat transfer Engineering, vol. 28, no. 8-9, pp. 788-794, 2007.

2 [17] Yang C.Y., and Liu W.C, Development of a mini liquid cooling system for high-heat-flux

3 electronic devices, Heat Transfer Engineering, vol. 32, no. 7-8, pp. 690-696, 2011.

4 [18] Léal, L., Topin, F., Lavieille, P., Tadrist, L., and Miscevic, M., Simultaneous integration,

5 control and enhancement of both fluid flow and heat transfer in small scale heat exchangers: A

6 numerical study, International Com. onn Heat and Mass Transfer, vol. 49, pp. 36-40, 2013.

7 [19] Kumar, P., Schmidmayer, K., Topin, F., and Miscevic, M., Heat transfer enhancement by

8 dynamic corrugated heat exchanger wall: Numerical study, Journal of Physics: Conference

9 Series, vol. 745, pp. 32-61, 2016.

10 [20] Saeed M., and Kim M.H., Header design approaches for mini-channel heatsinks using 11 analytical and numerical methods, Applied Thermal Engineering, vol. 110, pp. 1500-1510, 2017. 
Table 1. Presentation of global thermal and flow properties for different mesh sizes for number of time step per period $T S=50$.

\begin{tabular}{|c|c|c|c|c|c|c|}
\hline BMS & $\begin{array}{c}\dot{m} \\
(\mathrm{~g} / \mathrm{s})\end{array}$ & $\begin{array}{c}T_{w} \\
(\mathrm{~K})\end{array}$ & $\begin{array}{c}T_{m f} \\
(\mathrm{~K})\end{array}$ & $\begin{array}{c}\langle h\rangle \\
\left(\mathrm{W} / \mathrm{m}^{2} \mathrm{~K}\right)\end{array}$ & $\begin{array}{c}T_{f i} \\
(\mathrm{~K})\end{array}$ & $\begin{array}{c}T_{f o} \\
(\mathrm{~K})\end{array}$ \\
\hline $3 \mathrm{~mm}$ & 1.11 & 312.51 & 307.87 & 13829 & 301.1 & 313.8 \\
\hline $2 \mathrm{~mm}$ & 1.10 & 312.51 & 307.85 & 13765 & 301.1 & 313.8 \\
\hline
\end{tabular}

3

4

5

6

7 
Table 2. Presentation of global thermal and flow properties for different time steps for a characteristic mesh size $\mathrm{BMS}=2 \mathrm{~mm}$

\begin{tabular}{|c|c|c|c|c|c|c|}
\hline $\begin{array}{c}\mathrm{TS} \\
(-)\end{array}$ & $\begin{array}{c}\dot{m} \\
(\mathrm{~g} / \mathrm{s})\end{array}$ & $\begin{array}{c}T_{w} \\
(\mathrm{~K})\end{array}$ & $\begin{array}{c}T_{m f} \\
(\mathrm{~K})\end{array}$ & $\begin{array}{c}\langle h\rangle \\
\left(\mathrm{W} / \mathrm{m}^{2} \mathrm{~K}\right)\end{array}$ & $\begin{array}{c}T_{f i} \\
(\mathrm{~K})\end{array}$ & $\begin{array}{c}T_{f o} \\
(\mathrm{~K})\end{array}$ \\
\hline 20 & 1.14 & 311.7 & 307.3 & 14610 & 300.9 & 312.6 \\
\hline 50 & 1.10 & 312.5 & 307.9 & 13765 & 301.1 & 313.8 \\
\hline 75 & 1.10 & 312.7 & 308.0 & 13615 & 301.2 & 314.1 \\
\hline 100 & 1.06 & 312.8 & 308.0 & 13384 & 301.2 & 314.2 \\
\hline
\end{tabular}

2 
Table 3. Presentation of operating parameters (wave amplitude and frequency) on mass flow rate, surface and mean fluid temperature difference, heat transfer coefficient, inlet and outlet fluid temperatures.

\begin{tabular}{|c|c|c|c|c|c|c|}
\hline $\begin{array}{c}A \\
(\mu m)\end{array}$ & $\begin{array}{c}f_{r} \\
(H z)\end{array}$ & $\begin{array}{c}\dot{m} \\
(g / s)\end{array}$ & $\begin{array}{r}\Delta T_{m} \\
(K)\end{array}$ & $\begin{array}{c}\langle h\rangle \\
\left(\mathrm{W} / \mathrm{m}^{2} \mathrm{~K}\right)\end{array}$ & $\begin{array}{l}T_{f i} \\
(K)\end{array}$ & $\begin{array}{l}T_{f o} \\
(K)\end{array}$ \\
\hline 100 & 10 & 0.65 & 5.8 & 11054 & 301.75 & 321.94 \\
\hline 100 & 20 & 1.31 & 5.03 & 12756 & 301.06 & 311.94 \\
\hline 100 & 30 & 1.96 & 4.56 & 14071 & 300.74 & 308.35 \\
\hline 100 & 40 & 2.64 & 4.24 & 15154 & 300.60 & 306.46 \\
\hline 100 & 50 & 3.34 & 4.01 & 16007 & 300.50 & 305.32 \\
\hline 85 & 10 & 0.55 & 5.43 & 11808 & 301.88 & 325.87 \\
\hline 85 & 20 & 1.10 & 4.66 & 13765 & 301.12 & 313.80 \\
\hline 85 & 30 & 1.68 & 4.2 & 15261 & 300.83 & 309.63 \\
\hline 85 & 40 & 2.18 & 3.91 & 16381 & 300.62 & 307.40 \\
\hline 75 & 10 & 0.49 & 5.1 & 12580 & 301.94 & 329.17 \\
\hline 75 & 20 & 0.97 & 4.39 & 14606 & 301.22 & 315.65 \\
\hline 75 & 30 & 1.46 & 4 & 16045 & 300.87 & 310.79 \\
\hline 60 & 10 & 0.39 & 4.62 & 13879 & 302.09 & 336.41 \\
\hline 60 & 20 & 0.77 & 4 & 16067 & 301.37 & 319.66 \\
\hline 60 & 30 & 1.18 & 3.53 & 18167 & 301.00 & 313.50 \\
\hline 60 & 40 & 1.62 & 3.33 & 19285 & 300.77 & 310.16 \\
\hline
\end{tabular}




\section{List of figure captions}

2

4 constitute the manifolds.

5 Figure 2. Pictures of the heat exchanger after assembly: - left : top view (dug cover) - right : side

6 view. Dimension of the grooved part (42 $\times 49.5 \mathrm{~mm}$; thickness $1 \mathrm{~mm}$ (left) and $0.2 \mathrm{~mm}$ (right)

7 Figure 3. Sketch of the experimental apparatus.

8 Figure 4. Cross-section of dynamically corrugated micro-channel. The lower wall is subjected to 9 constant heat flux between $\mathrm{x} 1$ and $\mathrm{x} 7$, the gap $\mathrm{g}$ is the minimum height of the channel. Upper 10 profiles are drawn for 2 different amplitudes and same gap

11 Figure 5. Mesh view micro-channel at an arbitrary time. Dimension in the z-direction is 12 magnified 50 times. The bottom wall is uniformly heated below the actuated zone (fine mesh), all 13 other walls are kept adiabatic.

14 Figure 6. Experimental and numerical pressure losses as a function of the mass flow rate for the 15 two channel thicknesses.

16 Figure 7. Calculated streamlines in the $1 \mathrm{~mm}$ channel heat exchanger in adiabatic configuration.

17 The liquid temperature is $20^{\circ} \mathrm{C}$. Blue: 0 - Red $0.1 \mathrm{~m} / \mathrm{s}$.

18 Figure 8. Calculated streamlines in the $200 \mu \mathrm{m}$ channel heat exchanger in adiabatic 19 configuration. The liquid temperature is $20^{\circ} \mathrm{C}$. Blue: 0 - Red $0.25 \mathrm{~m} / \mathrm{s}$.

20 Figure 9. Variation of the pressure loss in the heat exchangers as a function of the mass flow

21 rate. The symbols are the results obtained experimentally; The lines are the results given by Eq.

2210 with $\sum_{i} \xi_{i}=5$.

23 Figure 10. Comparison between regular and singular pressure drops in the $1 \mathrm{~mm}$ channel (top)

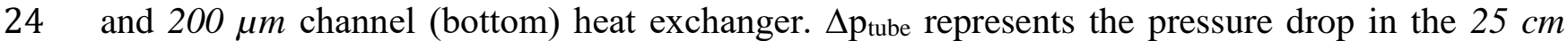
25 upstream and $25 \mathrm{~cm}$ downstream tube. 
1 Figure 11. Instantaneous velocity field: for $A_{0}=100 \mu \mathrm{m}$ and $f_{r}=10 \mathrm{~Hz}$. Color range (Blue : 0 -

2 Red $1 \mathrm{~m} / \mathrm{s}$ ). The vertical scale is magnified 100 times. Channel height is $10 \mu \mathrm{m}$ below center

3 actuator and total length is $7 \mathrm{~cm}$.

4 Figure 12. Influence of (top) Frequency for $A_{0}=100 \mu \mathrm{m}$ and, (bottom) Amplitude for $f_{r}=10 \mathrm{~Hz}$

5 on mass flow rate.

6 Figure 13. Influence of gap size on mass flow rate for $A_{0}=100 \mu \mathrm{m}$ and $f_{r}=10 \mathrm{~Hz}$.

7 Figure 14. Variation of the apparent thermal conductance as a function of the mass flow rate for

8 the two channel thicknesses. The same procedure is applied to calculate $G$ (eq. 8) from the

9 experiments and the numerical simulations; the maximum uncertainty is evaluated at $8 \%$.

10 Figure 15. Temperature field of the water at mid-height of the $200 \mu \mathrm{m}$ channel. The inlet

11 temperature is $23.5^{\circ} \mathrm{C}$, the mass flow rate is $1.5 \mathrm{~g} / \mathrm{s}$ and the heat flux is $62.7 \mathrm{~W}$.

12 Figure 16. Temperature field of the water at mid-height of the $1 \mathrm{~mm}$ channel. The inlet

13 temperature is $23.5^{\circ} \mathrm{C}$, the mass flow rate is $1.5 \mathrm{~g} / \mathrm{s}$ and the heat flux is $62.7 \mathrm{~W}$.

14 Figure 17. Instantaneous temperature field for $A_{0}=100 \mu \mathrm{m}$ and $f_{r}=10 \mathrm{~Hz}$. Vertical scale is

15 magnified 100 times. Cold fluid fills the space below $1^{\text {st }}$ actuator (here ascending) with small

16 backflow due to the $2^{\mathrm{d}}$ actuator "pressing" the fluid on surface (height is about $50 \mu \mathrm{m}$ ). The fluid

17 is mainly driven toward $3^{\text {rd }}$ actuator and outlet.

18 Figure 18. Influence of (a) Frequency for $A_{0}=100 \mu \mathrm{m}$ and, (b) Amplitude for $f_{r}=10 \mathrm{~Hz}$ on heat

19 transfer coefficient.

20 Figure 19. Thermal conductance as a function of the mass flow rate: comparison between the

21 numerical actuated prototype with $A_{0}=100 \mu \mathrm{m}$, the $200 \mu \mathrm{m}$ and the $1 \mathrm{~mm}$ reference static heat 22 exchangers. 
4

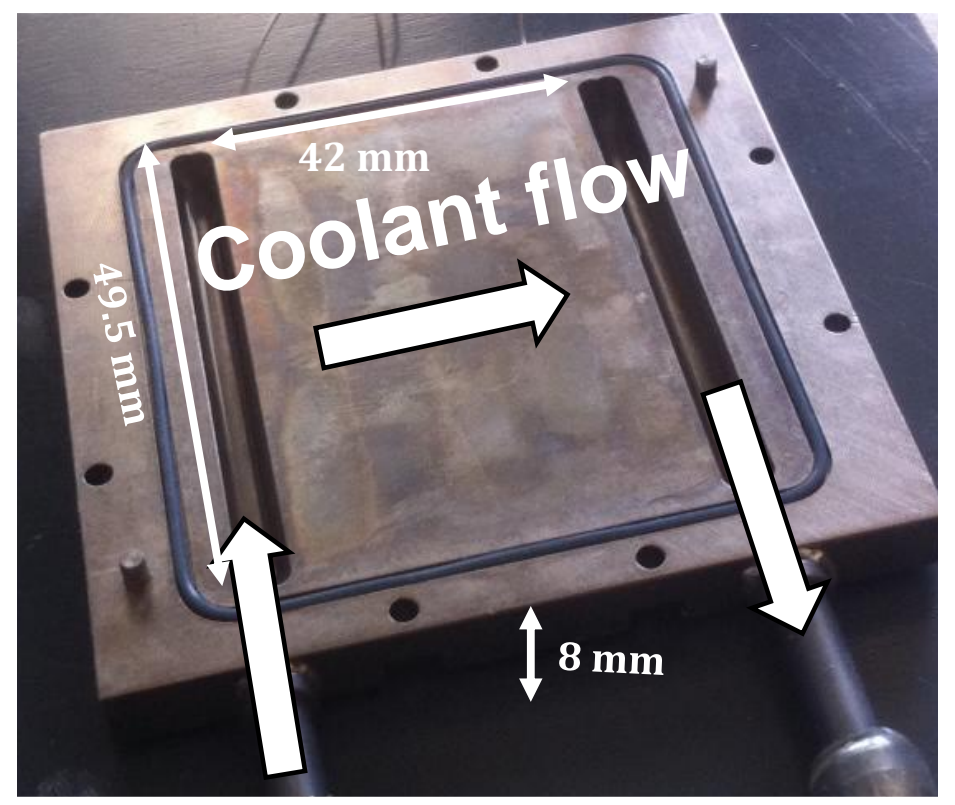

6

7 Figure 1. Picture of the bottom wall of the heat exchanger, made of copper. The two grooves 8 constitute the manifolds.

9

10

11 


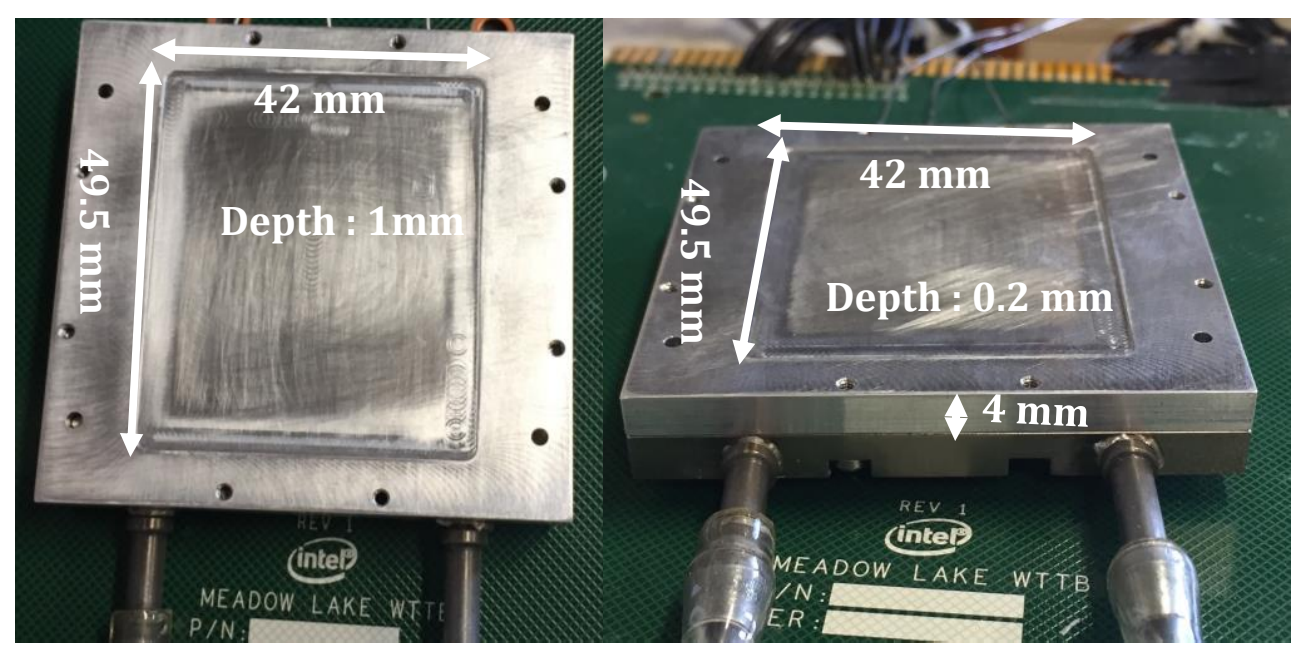

4

5 Figure 2. Pictures of the heat exchanger after assembly: top cover and bottom plate placed over a 6 CPU Thermal test Vehicle - left : top view (dug cover) - right : side view. Dimension of the 7 8 grooved part (42 $\times 49.5 \mathrm{~mm}$; thickness $1 \mathrm{~mm}$ (left) and $0.2 \mathrm{~mm}$ (right). 


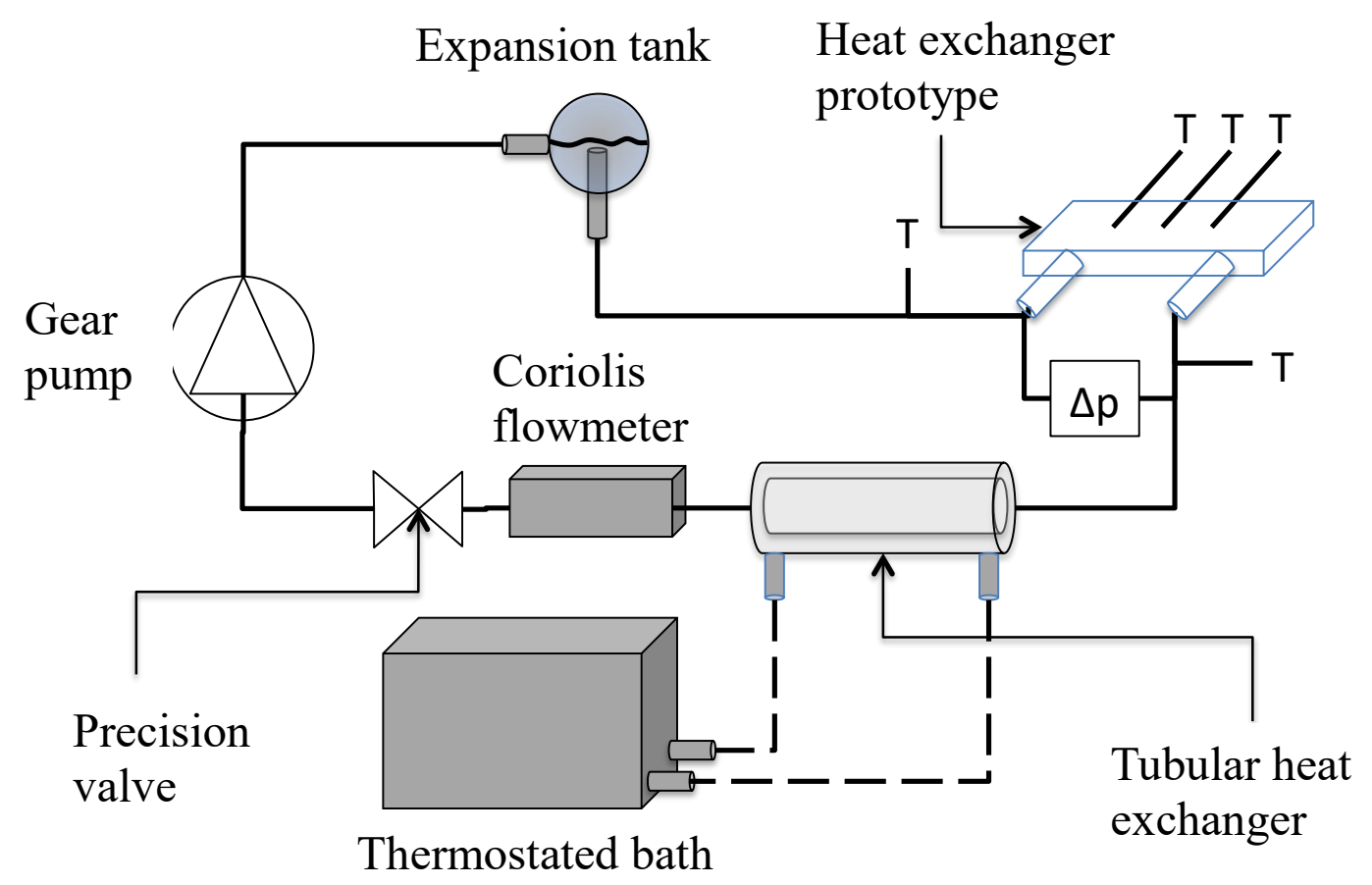

4

5

6

7

Figure 3. Sketch of the experimental apparatus. 


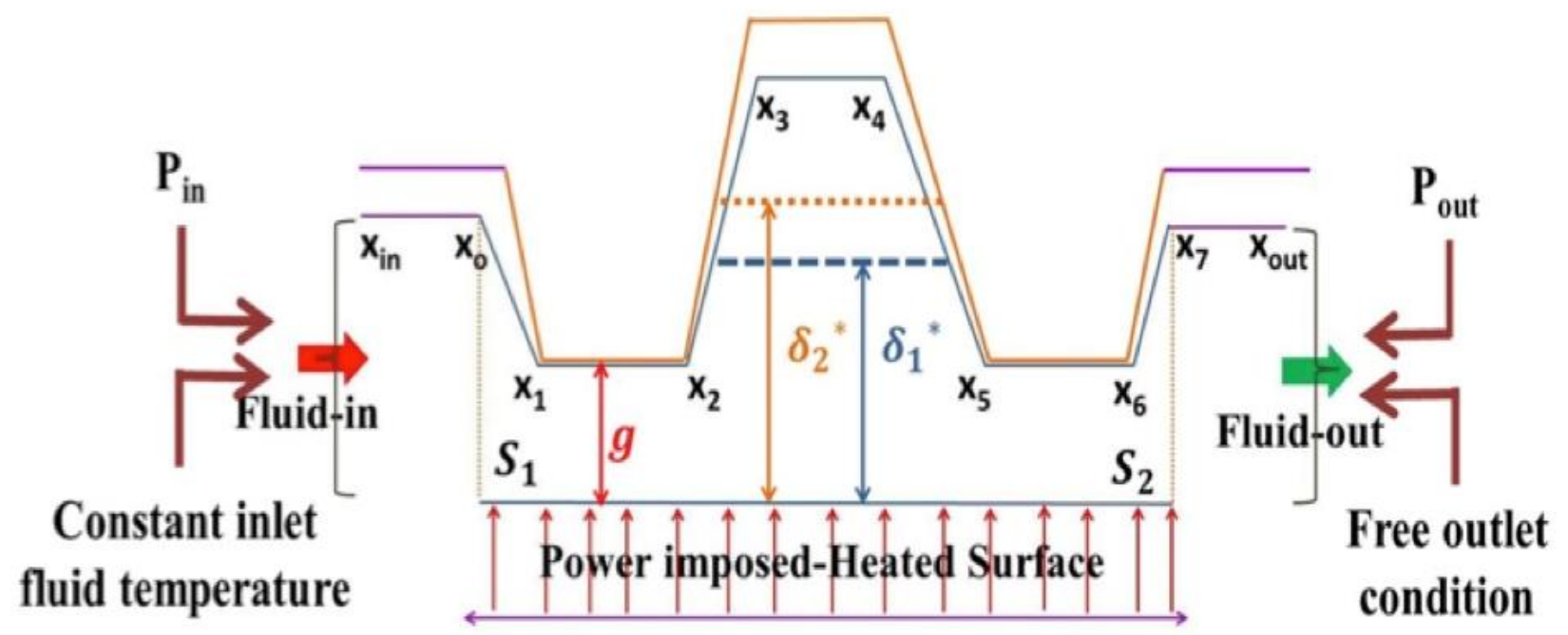

7 Figure 4. Cross-section of dynamically corrugated micro-channel. The lower wall is subjected to 8 constant heat flux between $\mathrm{x} 1$ and $\mathrm{x} 7$, the gap $\mathrm{g}$ is the minimum height of the channel. Upper 9 10 profiles are drawn for 2 different amplitudes and same gap 


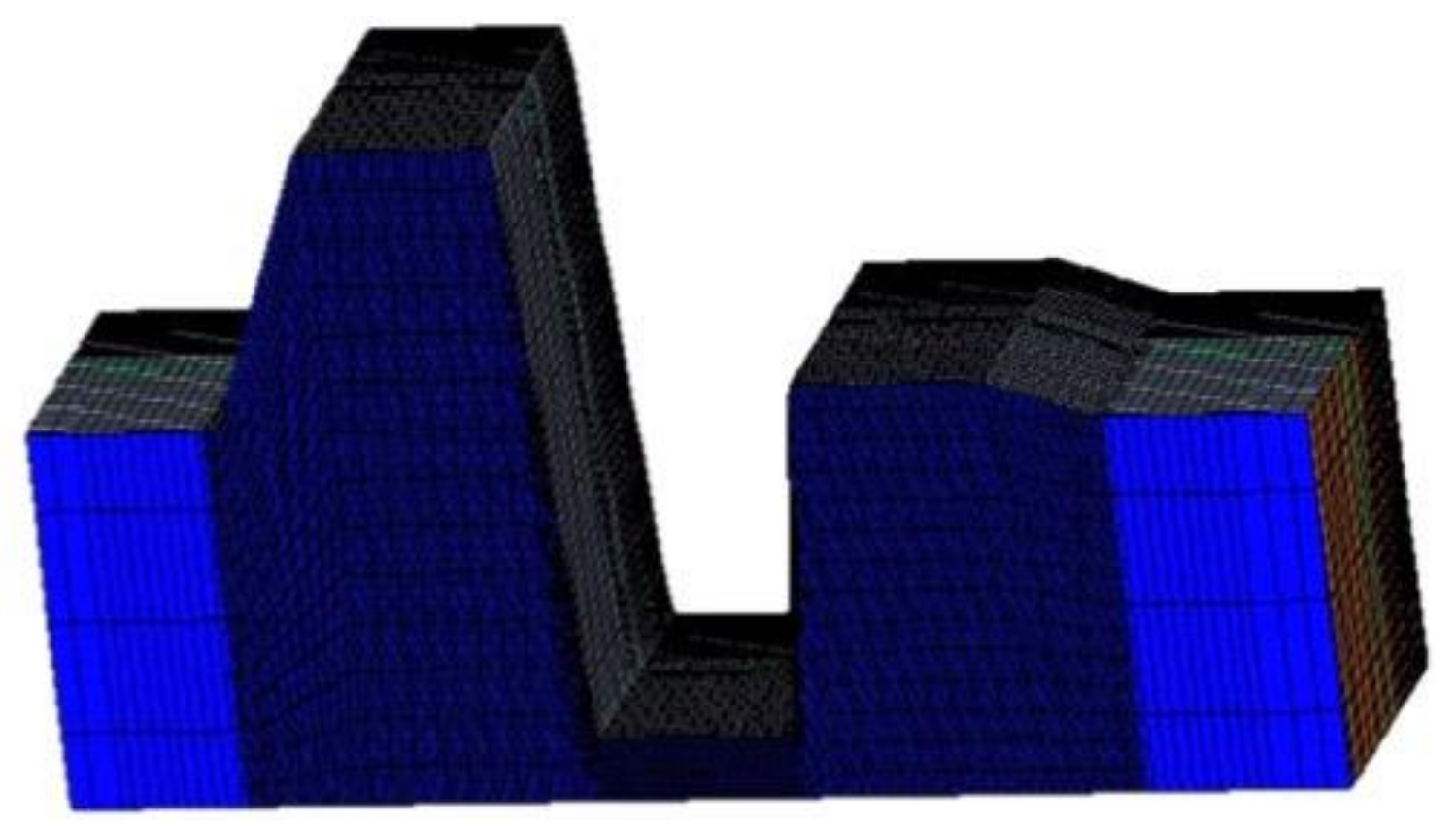

4 Figure 5. Mesh view micro-channel at an arbitrary time. Dimension in the z-direction is

5 magnified 50 times. The bottom wall is uniformly heated below the actuated zone (fine mesh), all 6 other walls are kept adiabatic.

7 


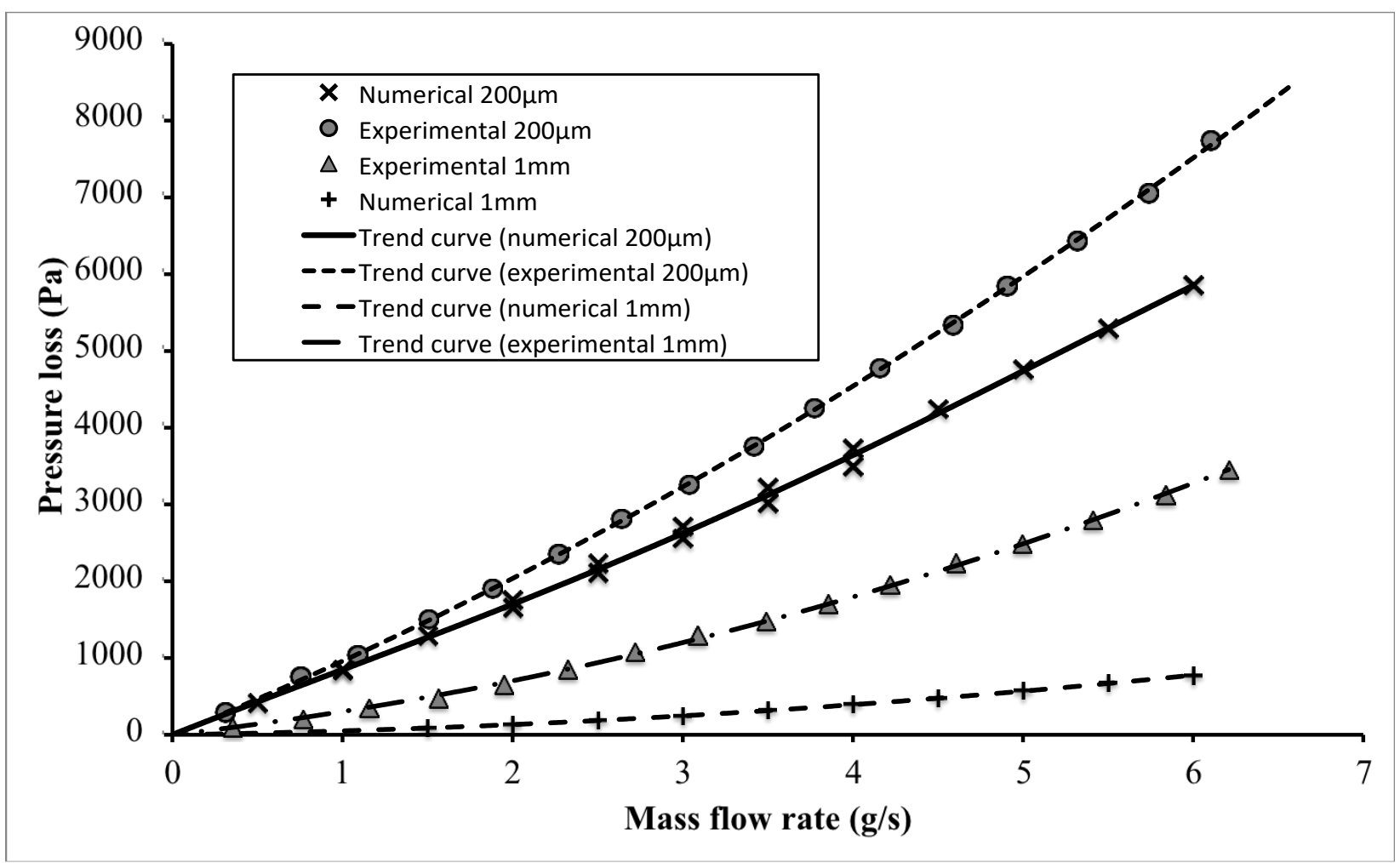

$4 \quad$ Figure 6. Experimental and numerical pressure losses as a function of the mass flow rate for the 5 two channel thicknesses. 


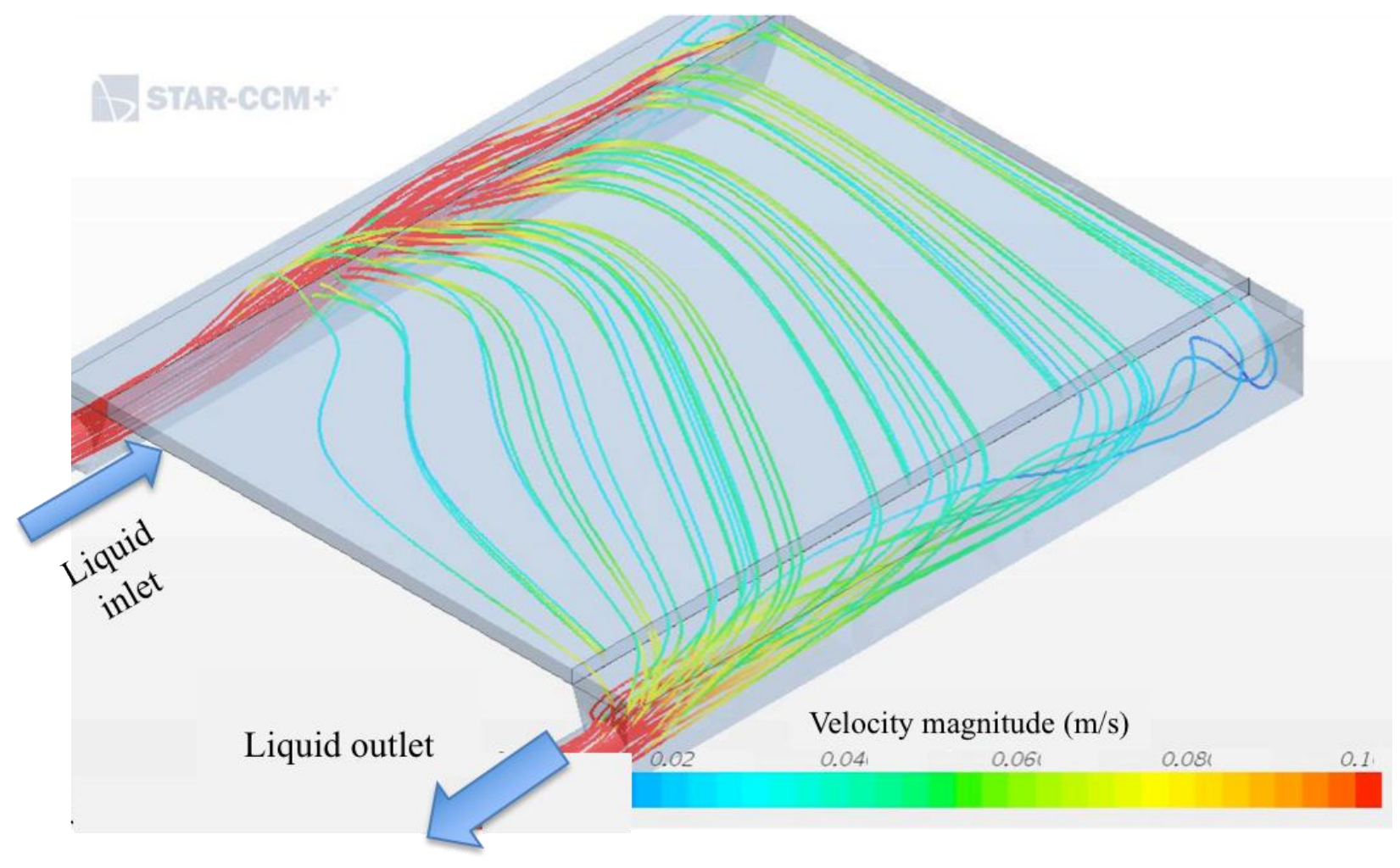

6 Figure 7. Calculated streamlines in the $1 \mathrm{~mm}$ channel heat exchanger in adiabatic configuration. 


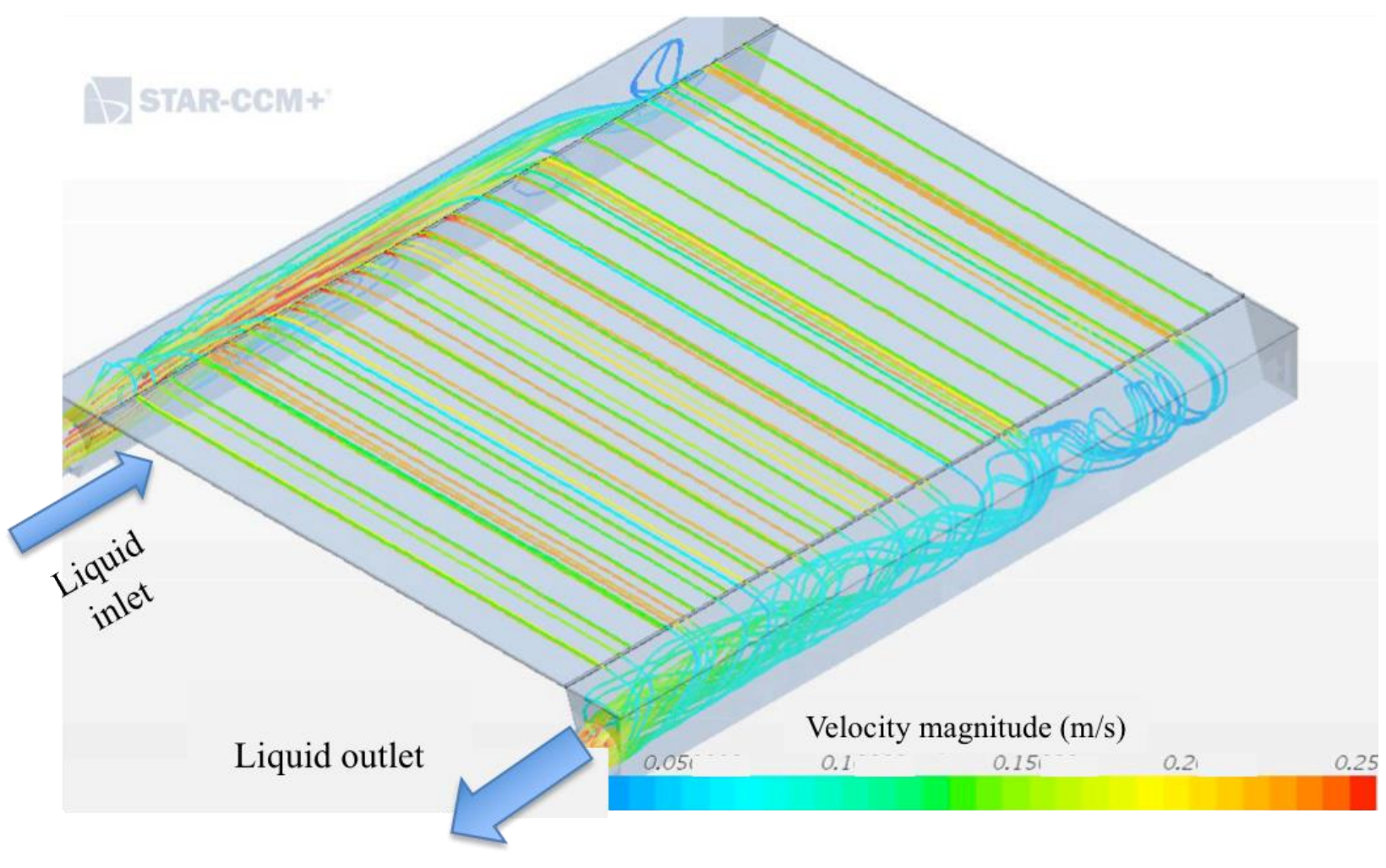

Figure 8. Calculated streamlines in the $200 \mu \mathrm{m}$ channel heat exchanger in adiabatic 


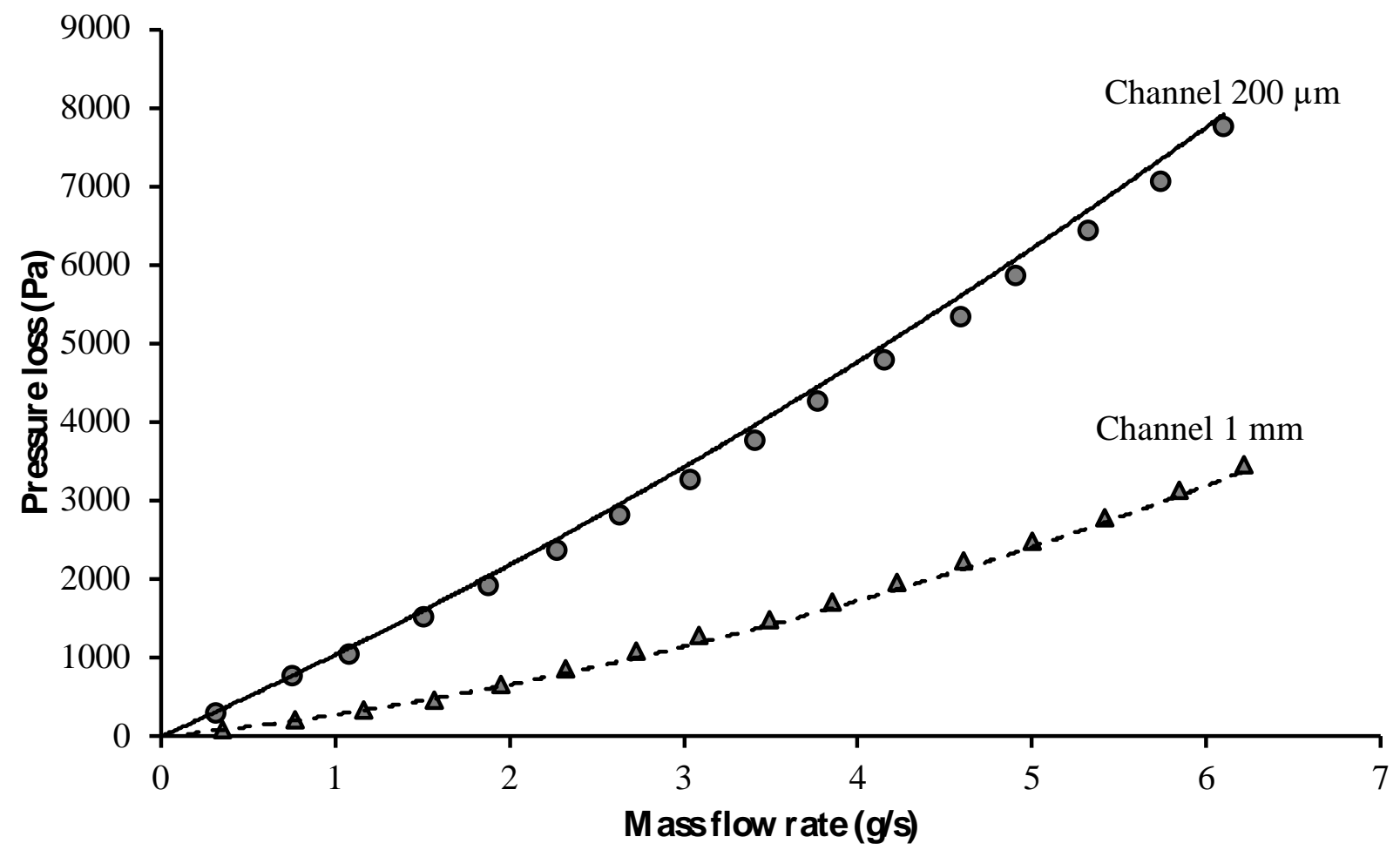

Figure 9. Variation of the pressure loss in the heat exchangers as a function of the mass flow 4 rate. The symbols are the results obtained experimentally; The lines are the results given by Eq. 5 10 with $\sum_{i} \xi_{i}=5$. 


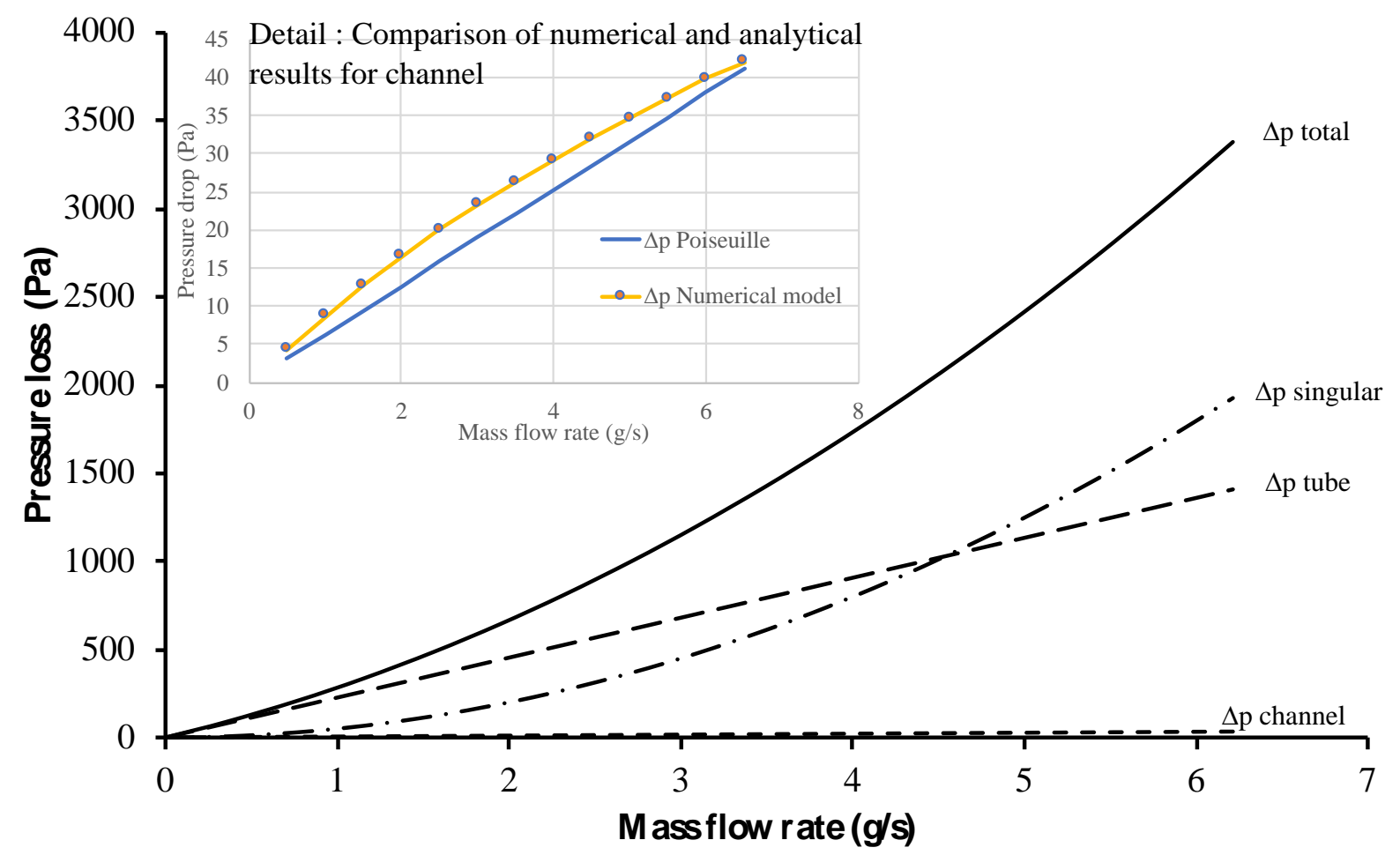

2

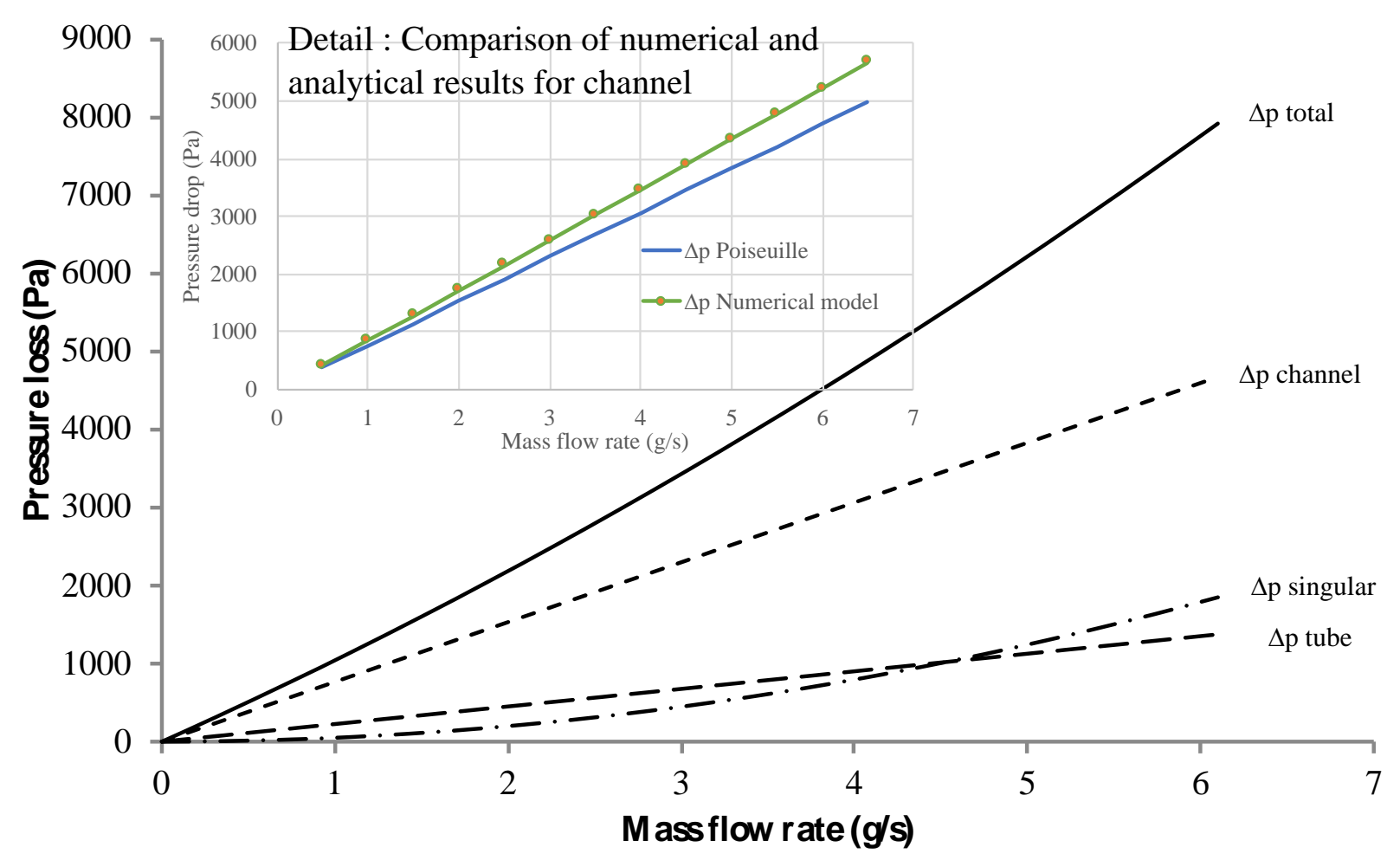

3

Figure 10. Comparison between regular and singular pressure drops in the $1 \mathrm{~mm}$ channel (top)

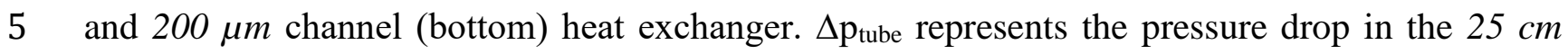


5 Figure 11. Instantaneous velocity field: for $A_{0}=100 \mu \mathrm{m}$ and $f_{r}=10 \mathrm{~Hz}$. Color range (Blue : 0 -

$6 \operatorname{Red} 1 \mathrm{~m} / \mathrm{s}$ ). The vertical scale is magnified 100 times. Channel height is $10 \mu \mathrm{m}$ below center 

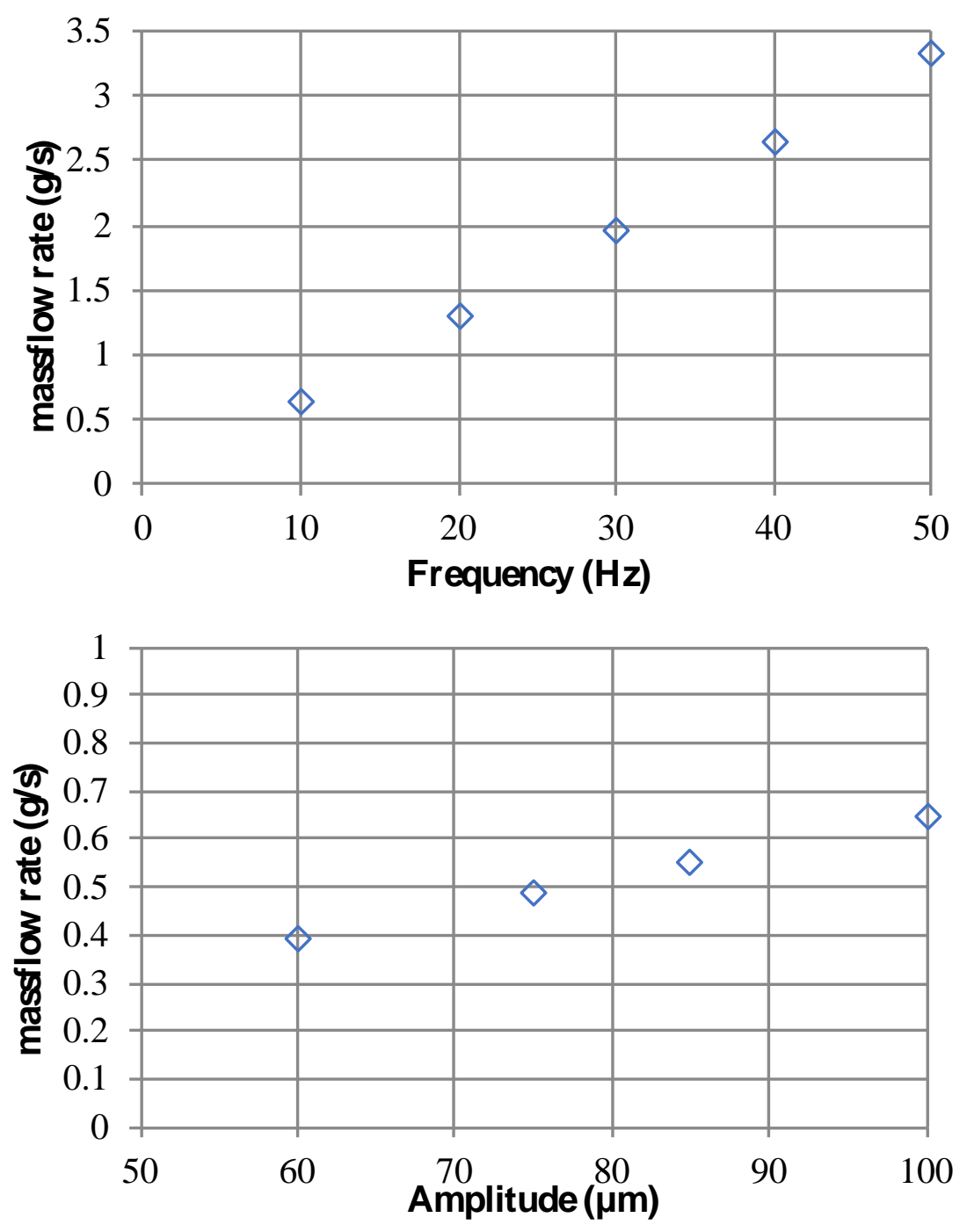

4 Figure 12. Influence of (top) Frequency for $A_{0}=100 \mu \mathrm{m}$ and, (bottom) Amplitude for $f_{r}=10 \mathrm{~Hz}$ 


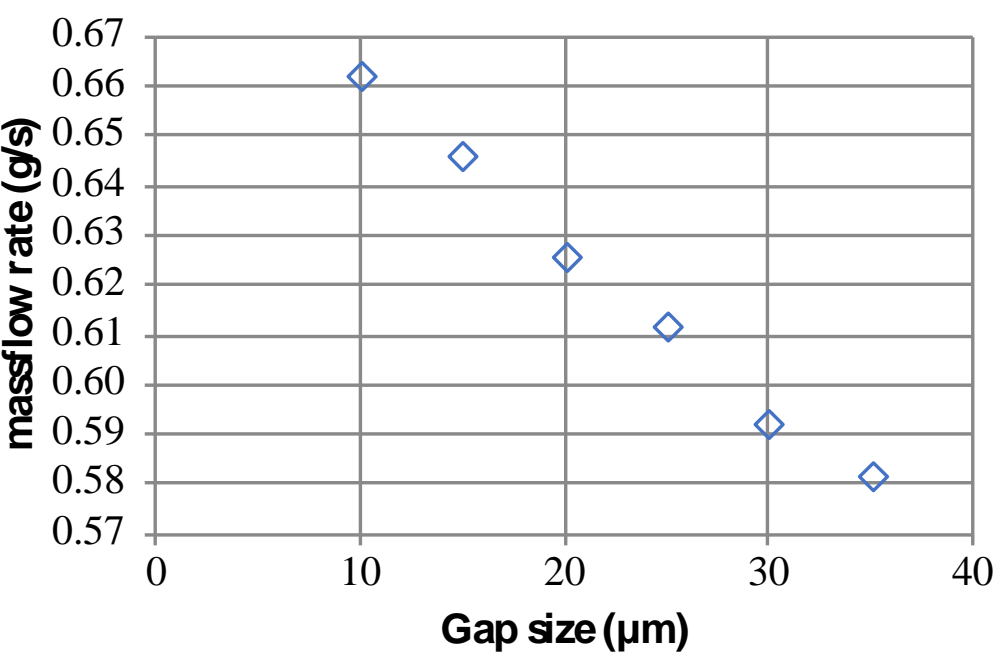

3 Figure 13. Influence of gap size on mass flow rate for $A_{0}=100 \mu \mathrm{m}$ and $f_{r}=10 \mathrm{~Hz}$.

4 


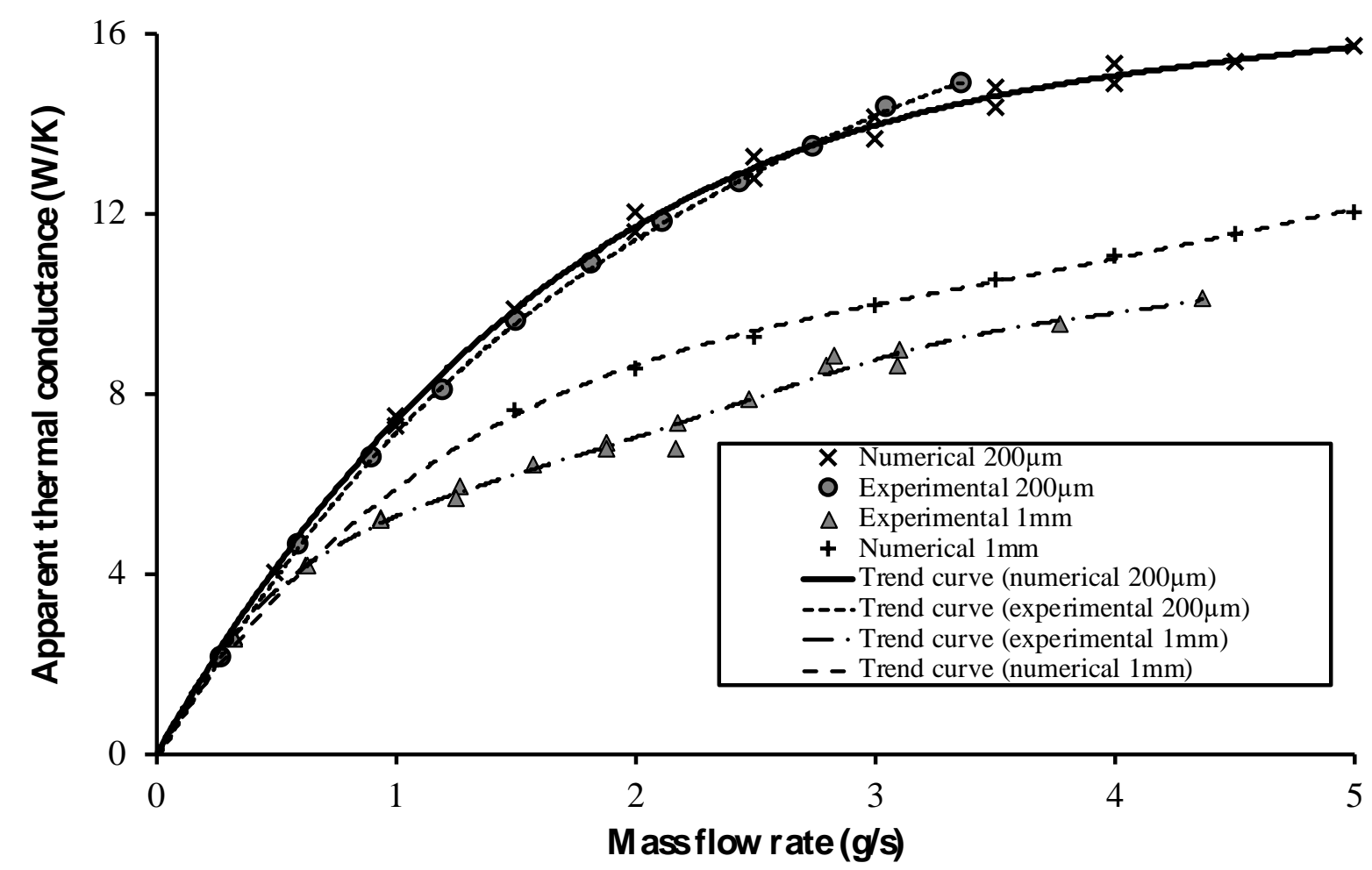

2
3

4 Figure 14. Variation of the apparent thermal conductance as a function of the mass flow rate for

5 the two channel thicknesses. The same procedure is applied to calculate $G$ (eq. 8) from the 6 experiments and the numerical simulations; the maximum uncertainty is evaluated at $8 \%$.

7 


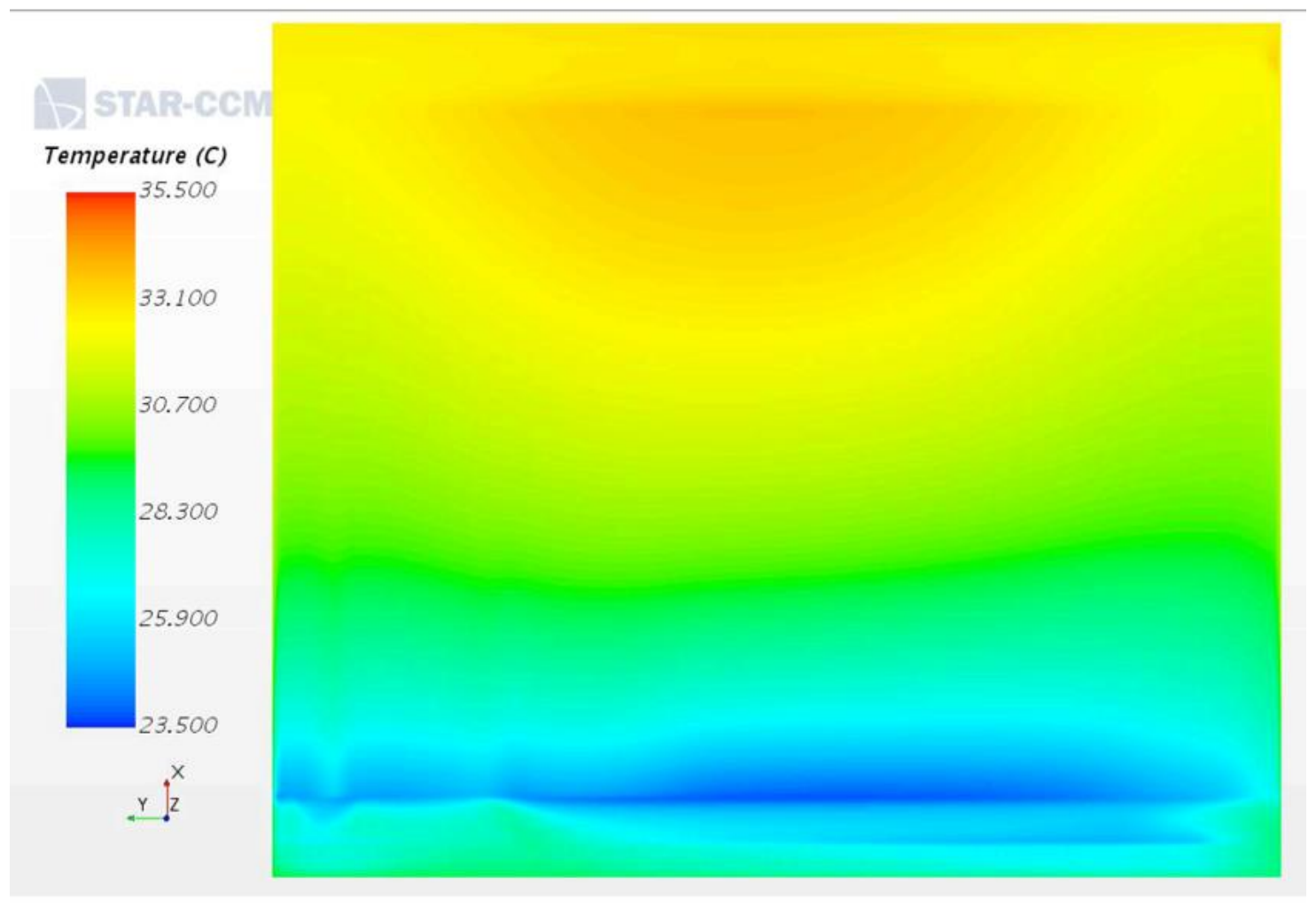

Figure 15. Temperature field of the water at mid-height of the $200 \mu \mathrm{m}$ channel. The inlet temperature is $23.5^{\circ} \mathrm{C}$, the mass flow rate is $1.5 \mathrm{~g} / \mathrm{s}$ and the heat flux is $62.7 \mathrm{~W}$. 
Figure 16. Temperature field of the water at mid-height of the $1 \mathrm{~mm}$ channel. The inlet temperature is $23.5^{\circ} \mathrm{C}$, the mass flow rate is $1.5 \mathrm{~g} / \mathrm{s}$ and the heat flux is $62.7 \mathrm{~W}$. 


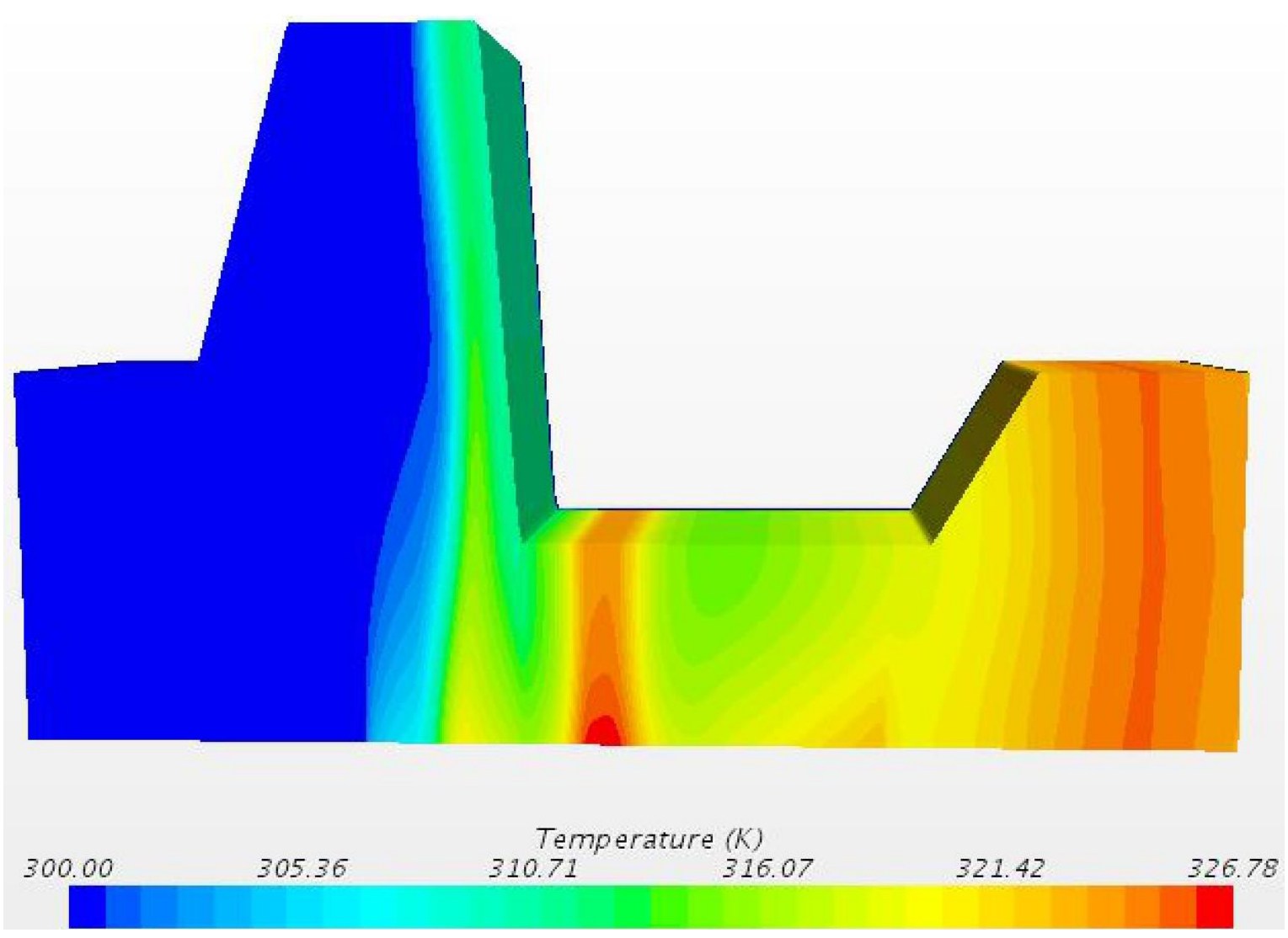

4

5 Figure 17. Instantaneous temperature field for $A_{0}=100 \mu \mathrm{m}$ and $f_{r}=10 \mathrm{~Hz}$. Vertical scale is 6 magnified 100 times. Cold fluid fills the space below $1^{\text {st }}$ actuator (here ascending) with small

7 backflow due to the $2^{\mathrm{d}}$ actuator "pressing" the fluid on surface (height is about $50 \mu \mathrm{m}$ ). The fluid 8 is mainly driven toward $3^{\text {rd }}$ actuator and outlet.

9 

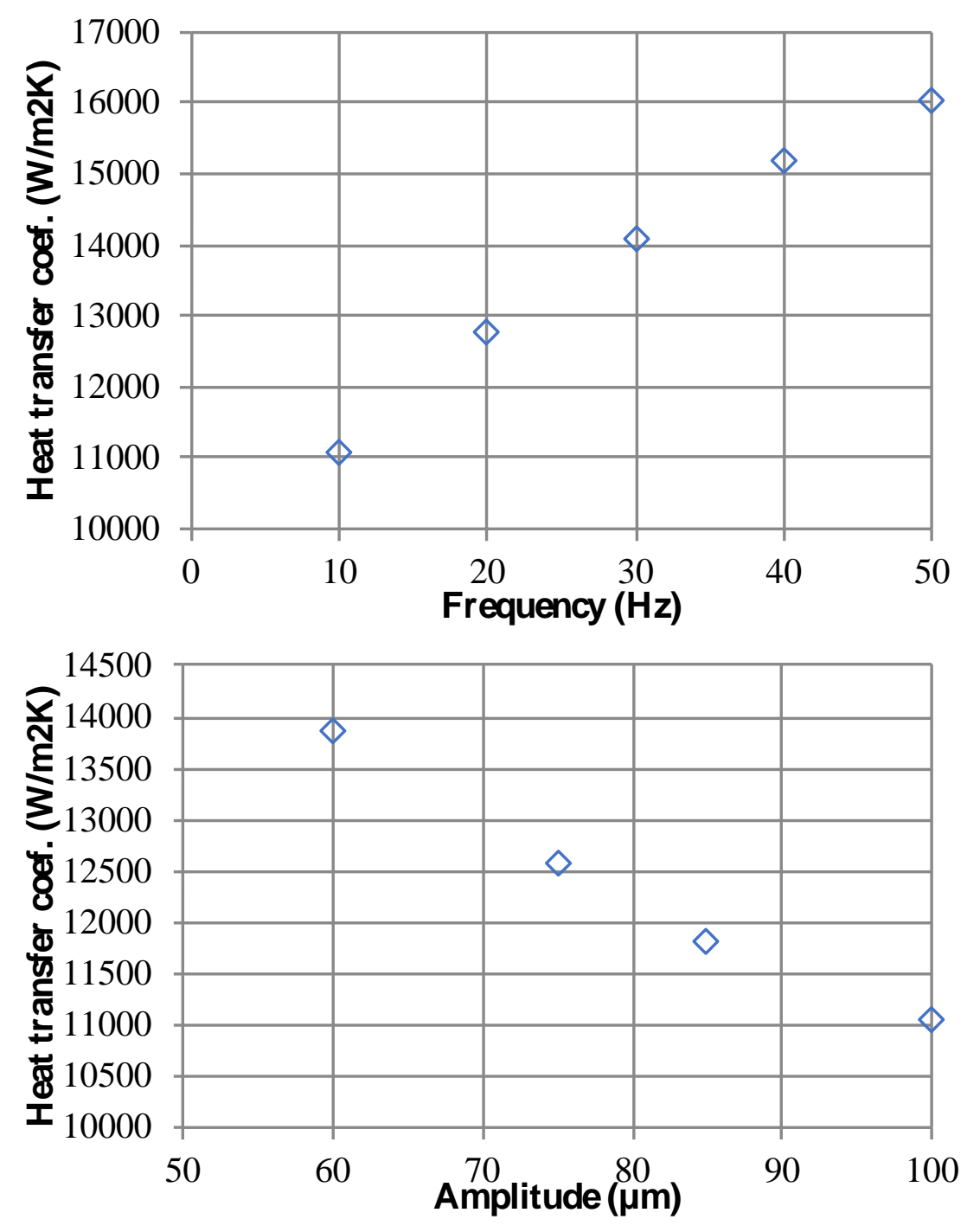

3 Figure 18. Influence of (a) Frequency for $A_{0}=100 \mu \mathrm{m}$ and, (b) Amplitude for $f_{r}=10 \mathrm{~Hz}$ on heat 4 transfer coefficient. 


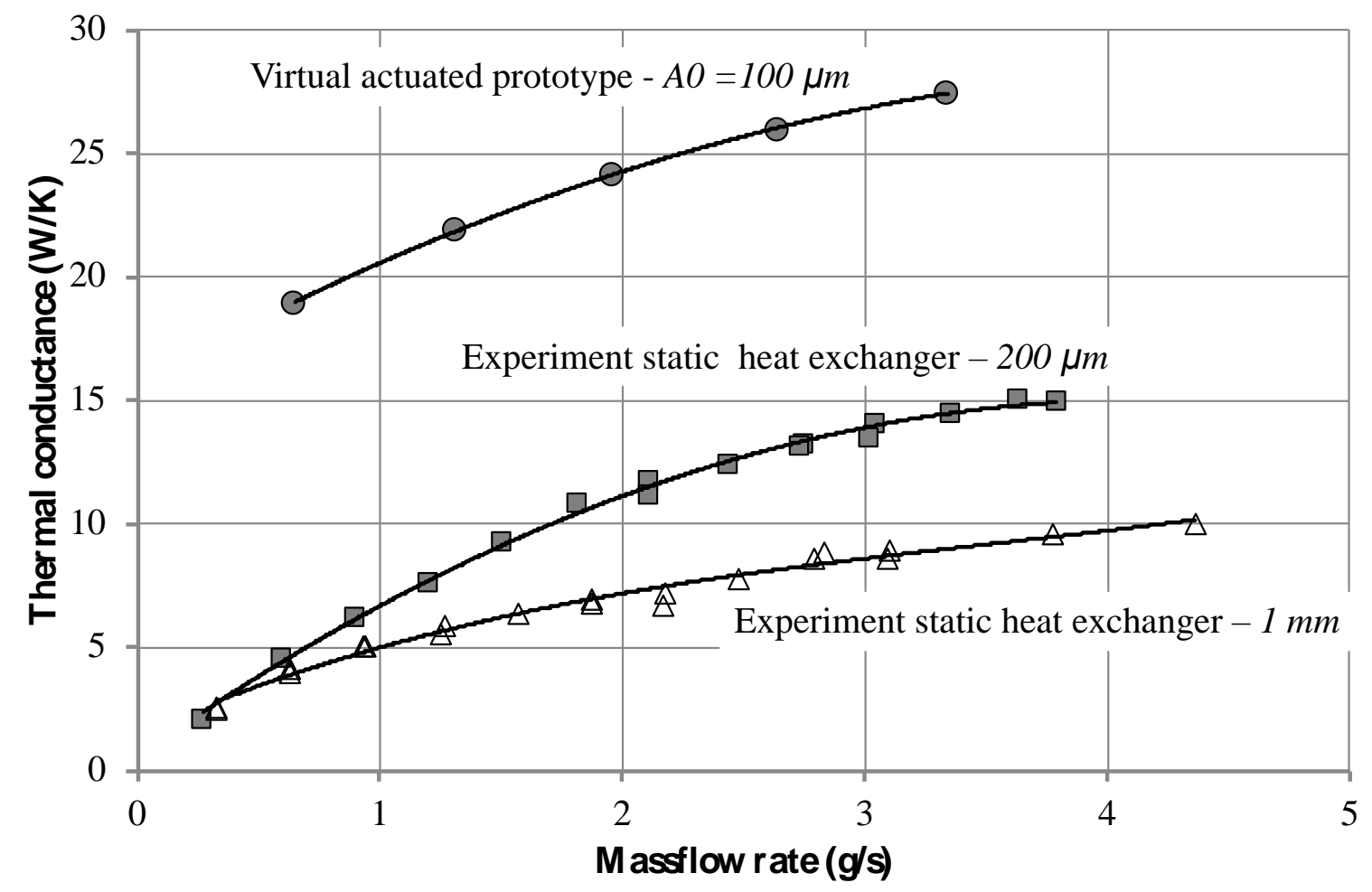

1

Figure 19. Thermal conductance as a function of the mass flow rate: comparison between the

3 numerical actuated prototype with $A_{0}=100 \mu \mathrm{m}$, the $200 \mu \mathrm{m}$ and the $1 \mathrm{~mm}$ reference static heat 4 exchangers.

5 

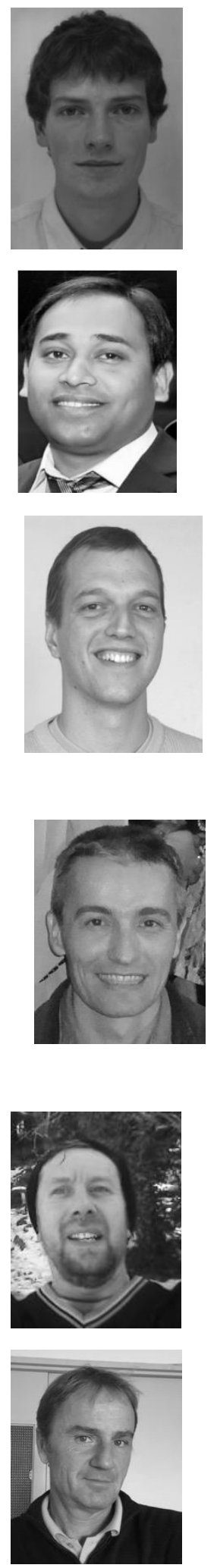

Julien Michel Fontaine graduated in electrical engineering and automatics from the engineering school ENSEEIHT at Toulouse, France, in 2014. He is currently a Ph.D. student at the Federal University Toulouse Midi-Pyrénées, France. The field of his research is piezoelectric actuation dedicated to micropumping and the improvement of heat transfer.

Prashant Kumar graduated in Computational Fluid Mechanics from Trinity college in Dublin, Ireland, in 2010. He obtained is Ph.D. entitled "Investigation of Kelvin-like solid foams for potential engineering applications: An attractive set of geometrical and thermo-hydraulic properties" in 2014 from Aix-Marseille Université, France. He then becomes involved in CFD analysis of dynamically deformed heat exchangers in IUSTI until 2017. He then joined ESILONAlcen in Toulouse.

Francois Pigache is an associate professor at LAPLACE, Toulouse University, France, since 2006. Before joining the LAPLACE, he obtained his Ph.D. in 2005 from the Université Sciences et technologies de Lille, France. He is involved in research in the areas of multiphysic modelling, the optimization of the piezoelectric transformers, and alternative applications of the electroactive materials for the surface functionalization.

Pascal Lavieille has been an assistant professor in the LAPLACE Laboratory, University Paul Sabatier of Toulouse, France since 2002. He obtained his Ph.D. in 2001 from the University H. Poincaré in Nancy, France. He is a specialist in optical diagnostic for the determination of temperatures fields and measurement of film thickness. His research interests are focused on phase change (condensation, boiling, capillary phenomena, wettability), and two-phase cooling systems.

Frédéric Topin is an associate professor at IUSTI, Aix-Marseille Université, France, since 1996. He obtained his Ph.D. in 1995 from the Université de Provence in Marseille, France. He is involved in research in the areas of transport phenomena in porous media (Structure Flows/Transfers - Reactions), dynamic fluid structure interaction, pore scale modeling of flow and phase change in solid foams and coupled phenomena such as bio fuel cells or stability of superconductor cables.

Marc Miscevic is an associate professor at LAPLACE, Toulouse University, France, since 1999. Prior coming to LAPLACE, he obtained his Ph.D. in 1997 from the Universite de Provence in Marseille, France. He is involved in research in the areas of active method of heat transfer enhancement, phase change in micro channels and microgravity (condensation, boiling, capillary phenomena, wettability), and two-phase cooling systems. 